\title{
Expanding the scope of surface grafted polymers using electroinitiated polymerization.
}

James D. Randall, ${ }^{a}$ Melissa K. Stanfield, ${ }^{a}$ Daniel J. Eyckens, ${ }^{a}$ Jean Pinson, ${ }^{b}$ and Luke C. Henderson.${ }^{*}$

a Institute for Frontier Materials, Deakin University, Geelong, VIC 3216, Australia.

b Université de Paris, ITODYS, CNRS, F-75006 Paris, France.

\section{Supporting Information}

SI-2 Cyclic Voltammogram (CV) grafting data for all samples.

SI-13 FTIR Spectra for all samples.

SI-33 Synthesis of 17.

SI-34 XPS spectra and elemental information for electrodes modified with monomers 6, 13, and 14.

SI-37 Examination of ferrocene film electrochemical activity. 
SEEP Cyclic Voltammogram (CV) graft for all samples.

Monomers displayed in spectrum are inset. Note that the scales have all been presented $\mu$ Amps to give relative scale to each of the graftings. The large variation in current is likely due to the ionisation of the monomeric species, and its presence in solution at very high concentrations.

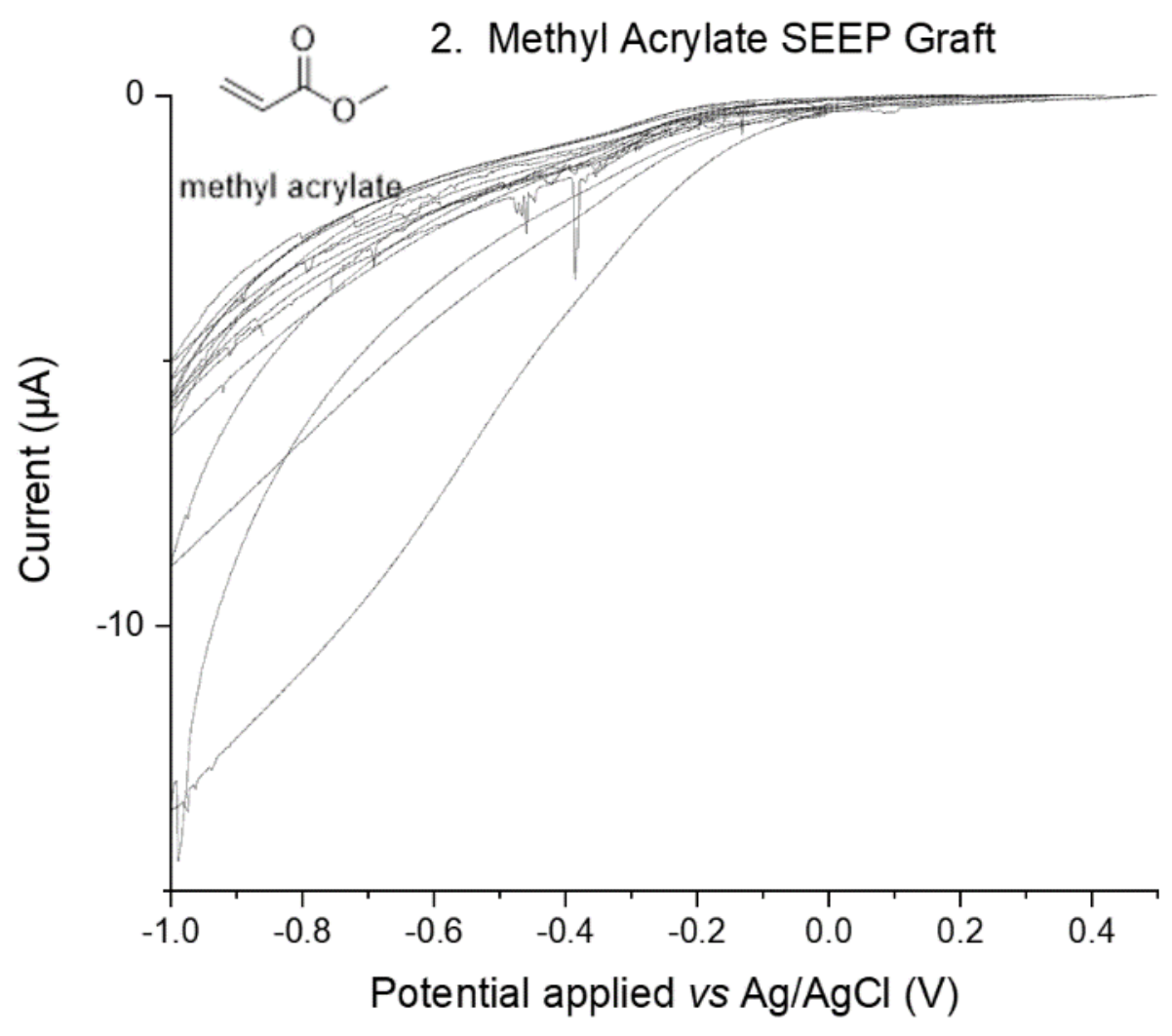


3. tert-butyl Acrylate SEEP Graft

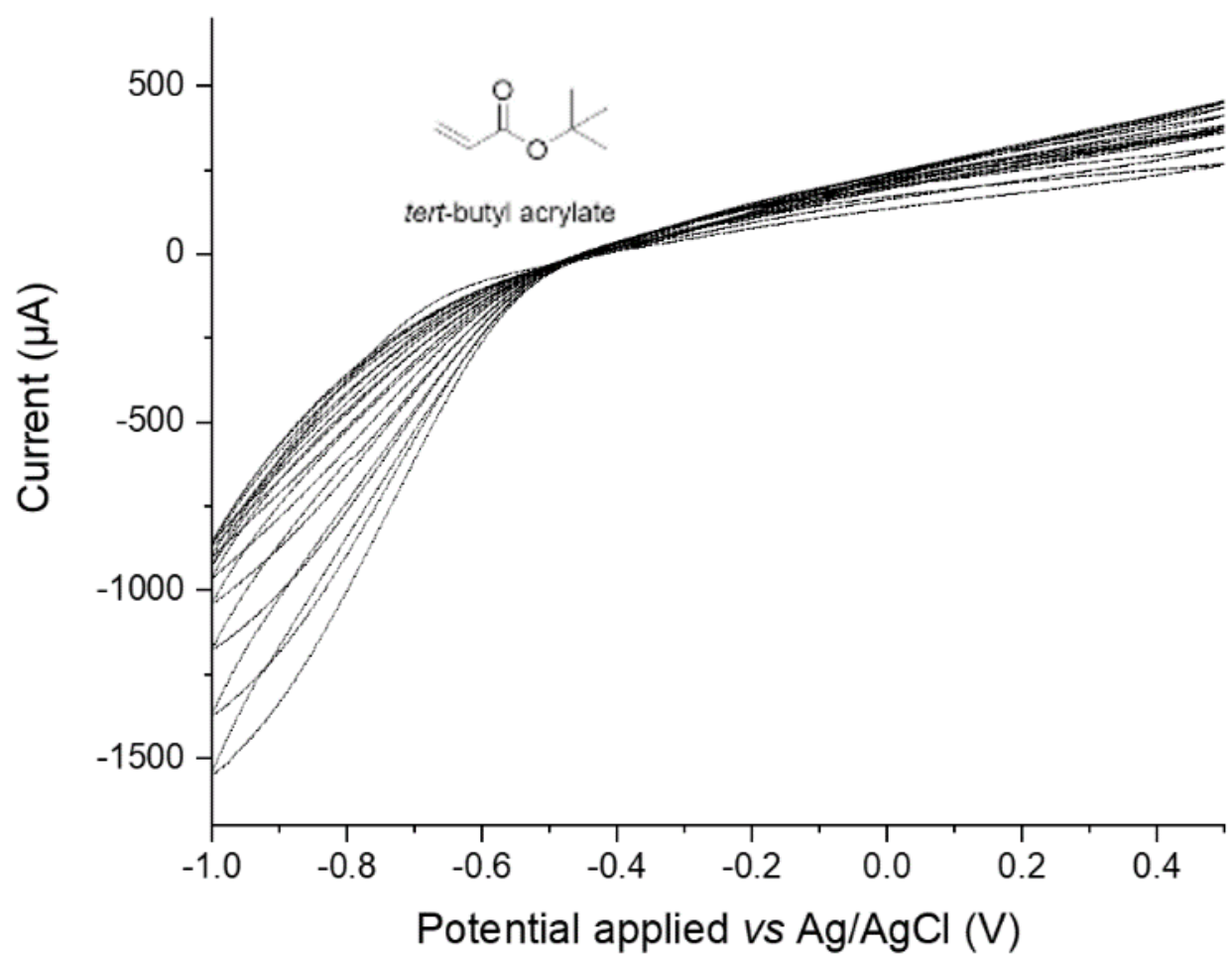

4. Octadecyl Acrylate SEEP Graft

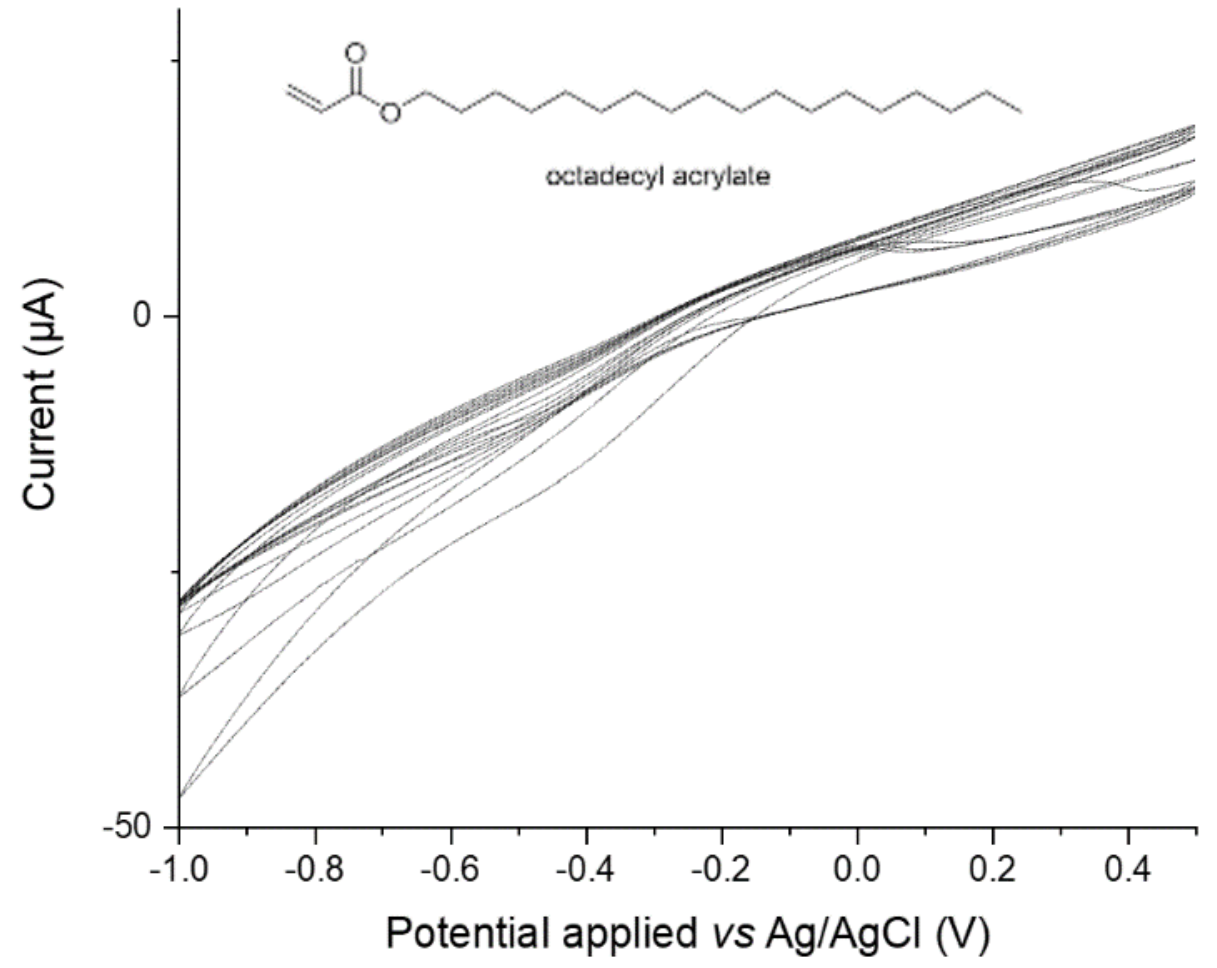



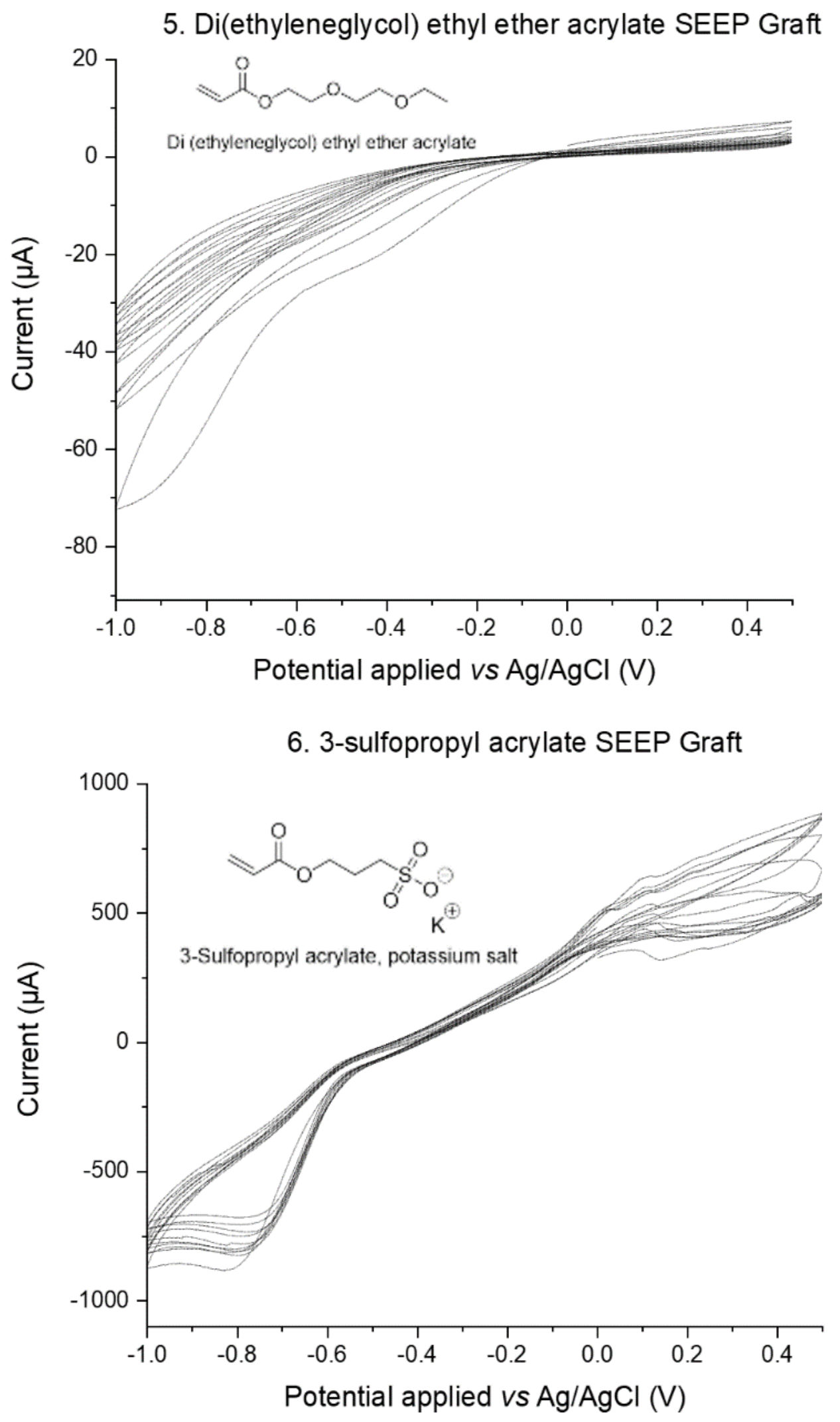

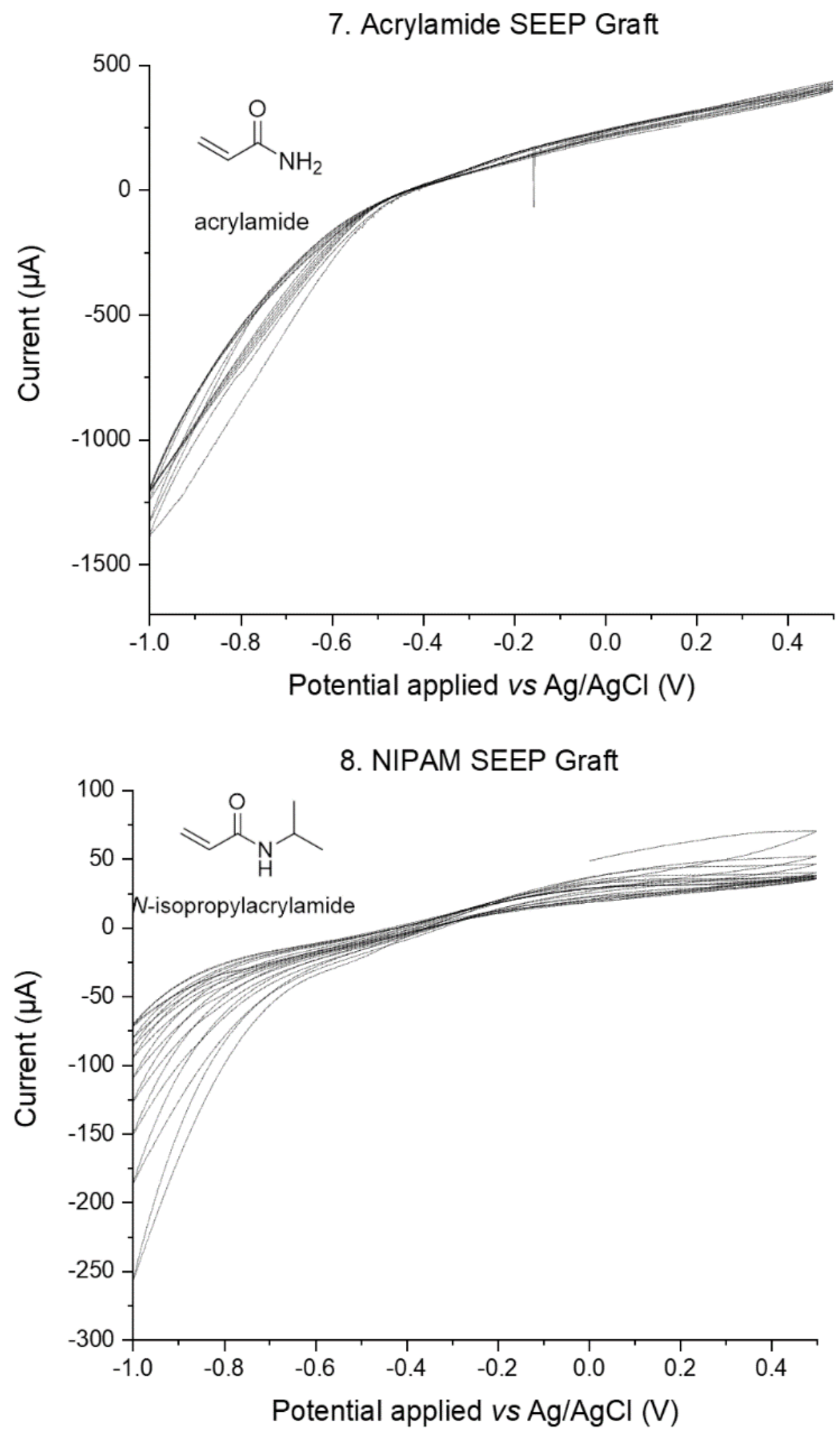

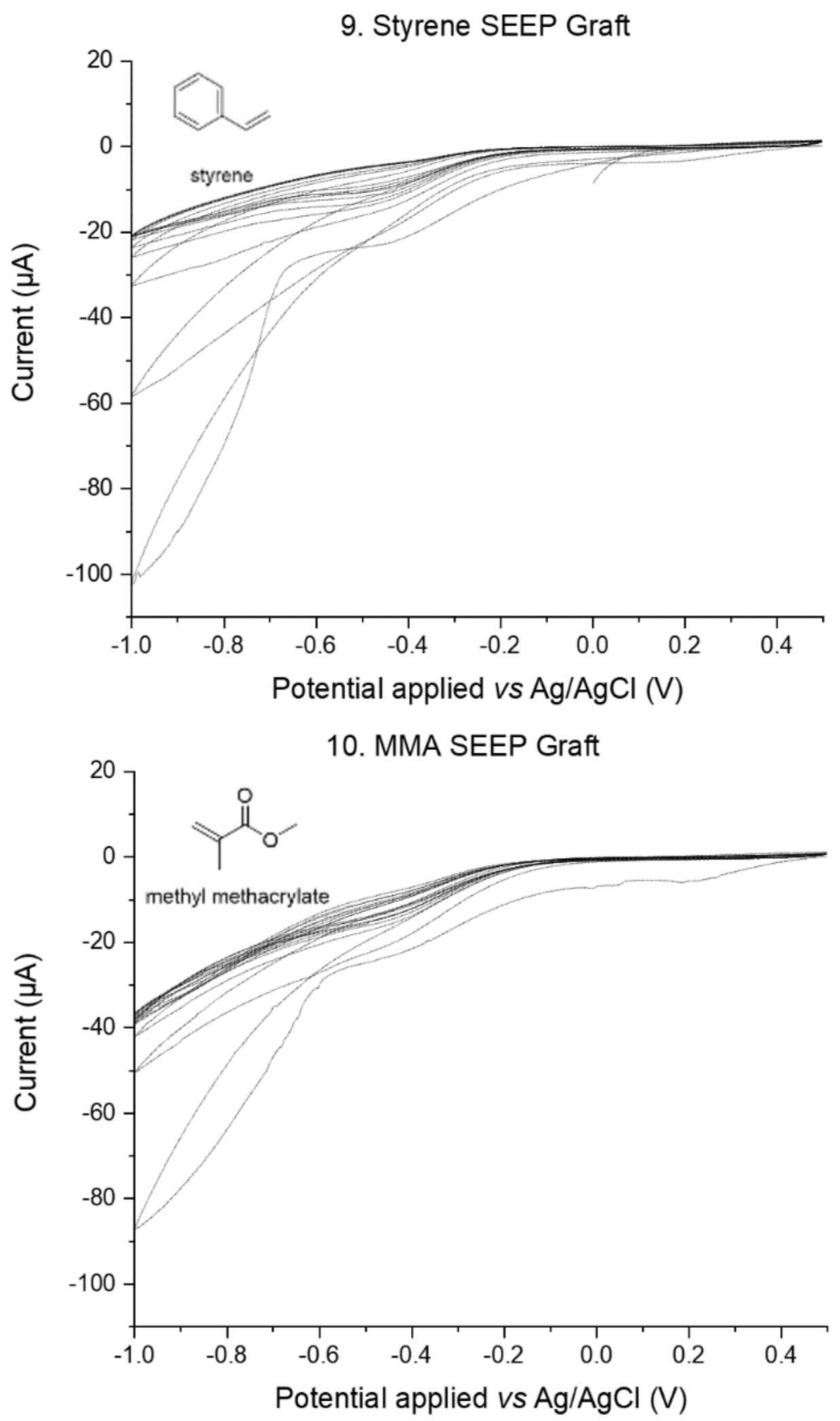

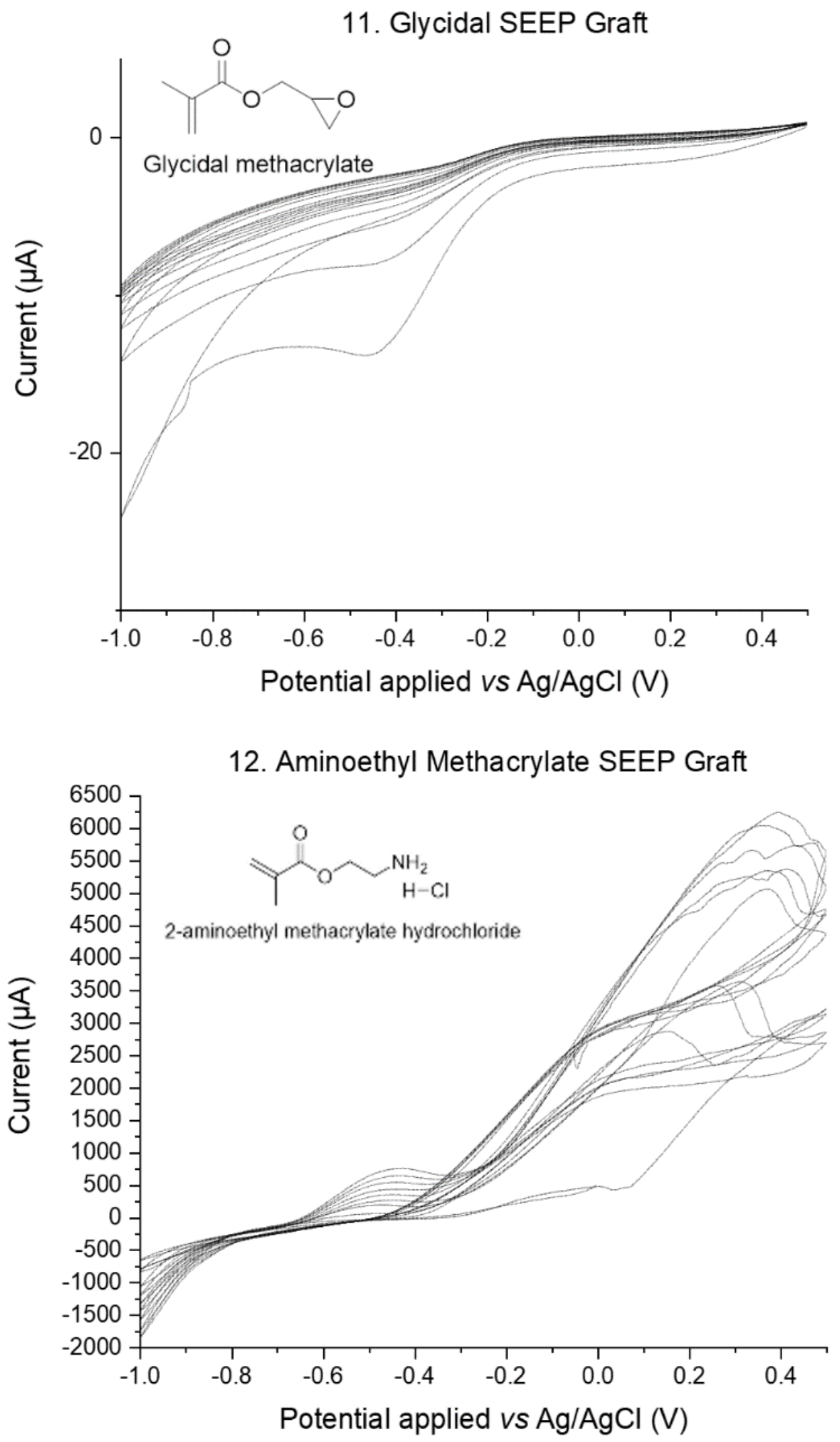
13. Trifluoroethyl Methacrylate SEEP Graft

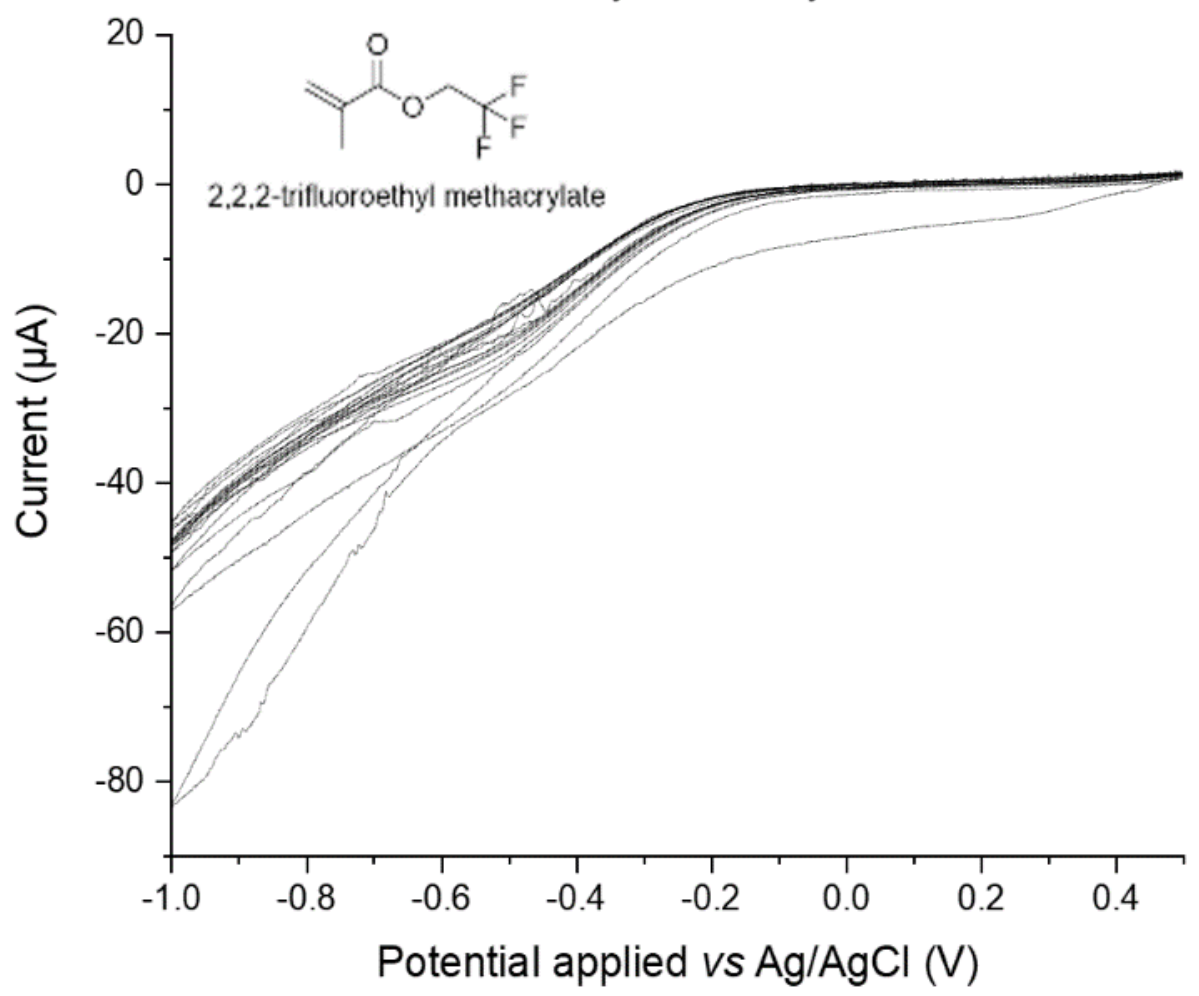


14. (Trimethylsilyloxy)ethyl Methacrylate SEEP Graft
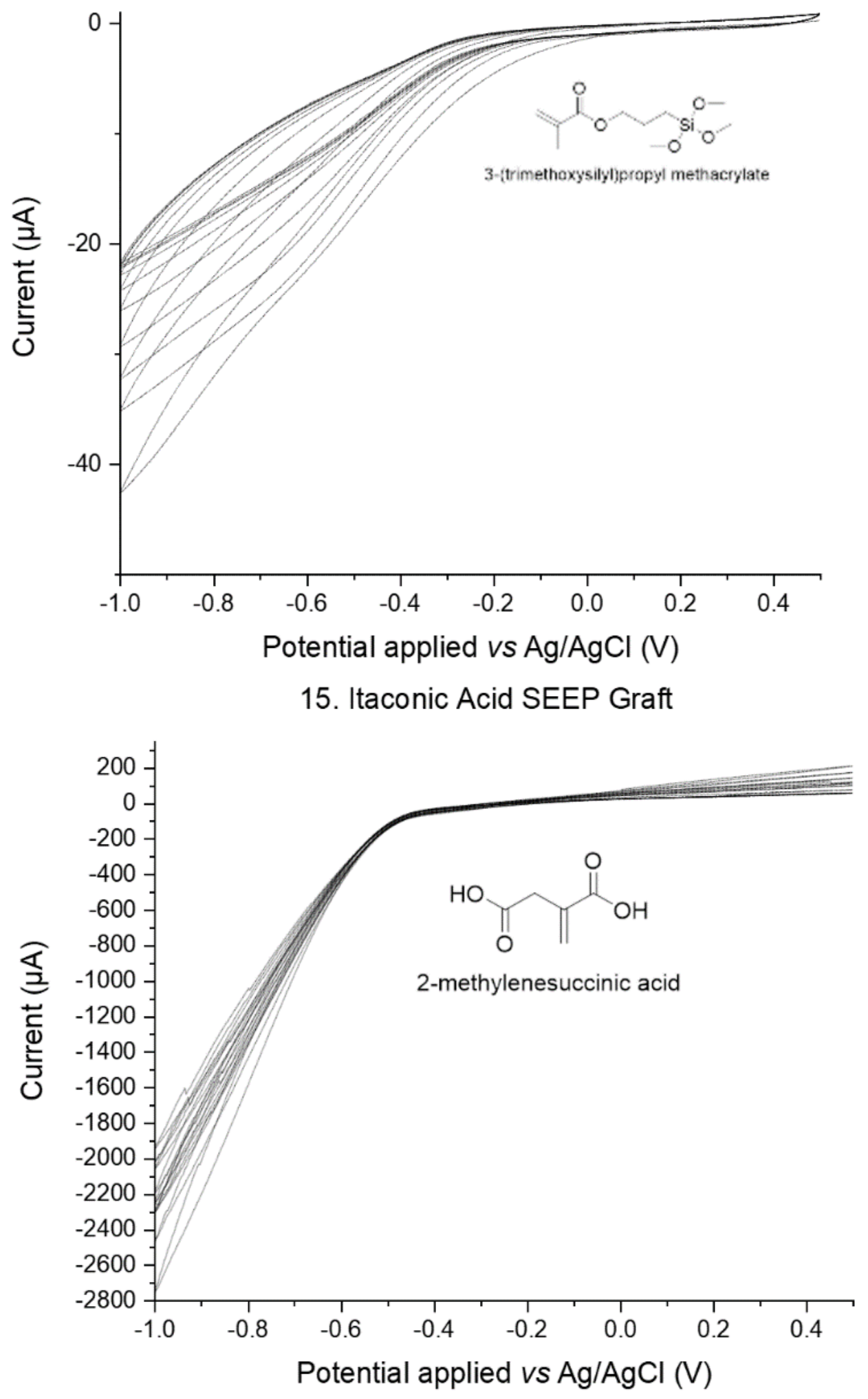
16. Methyl 2-fluoroacrylate SEEP Graft
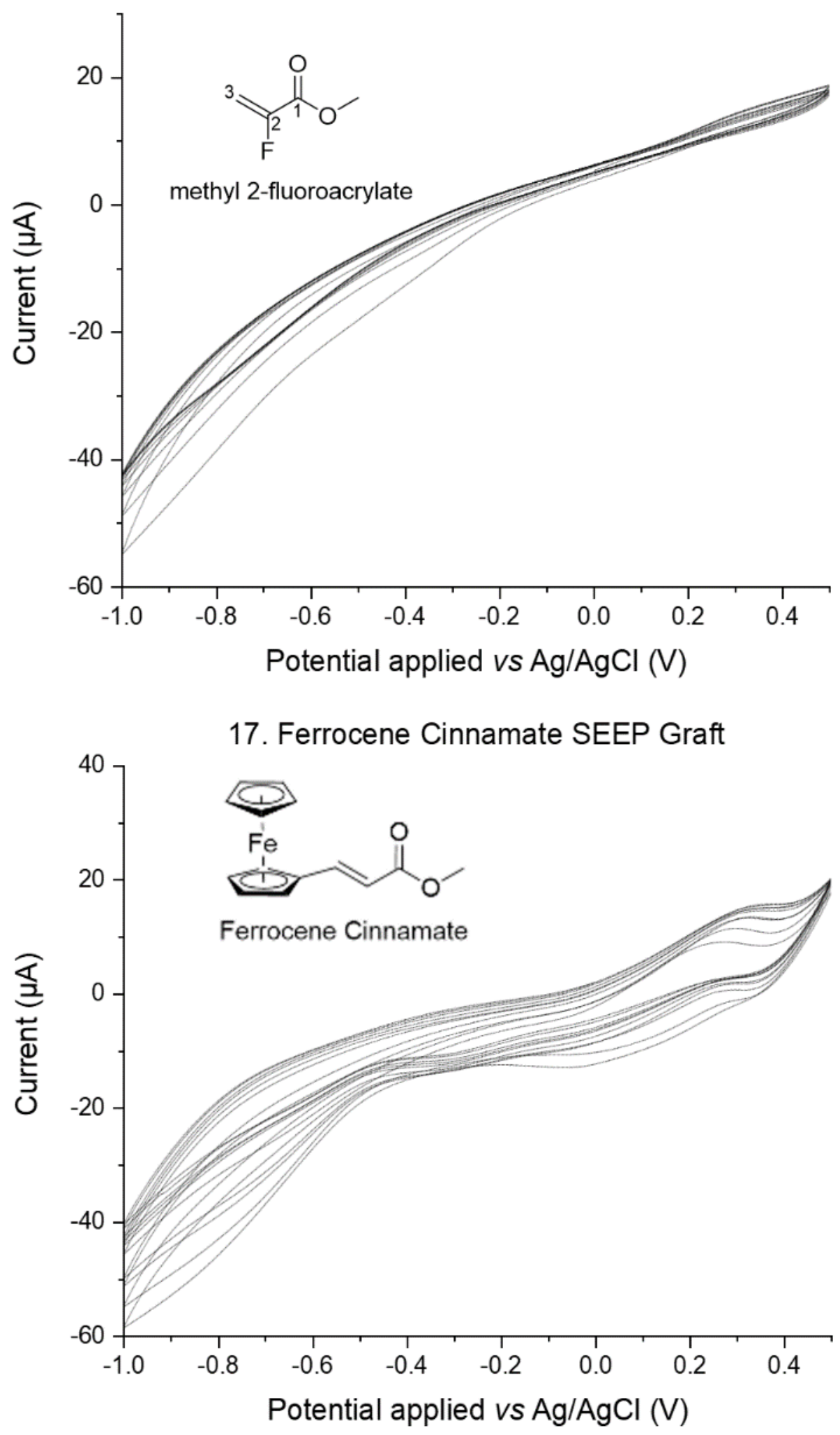
18. Poly(ethylene glycol) Diacrylate (mw 700) SEEP Graft

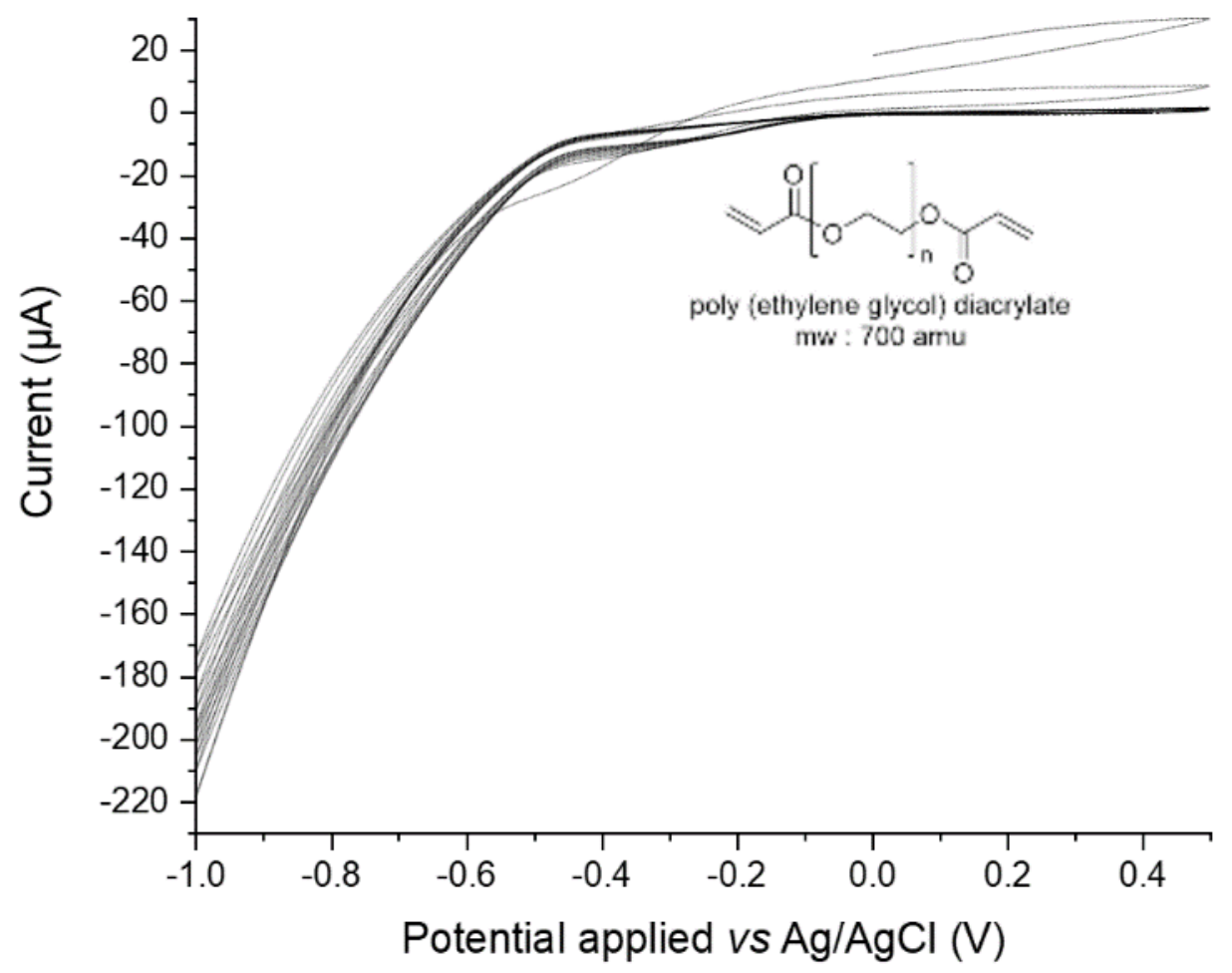

19. Methylenebis(acrylamide) SEEP Graft

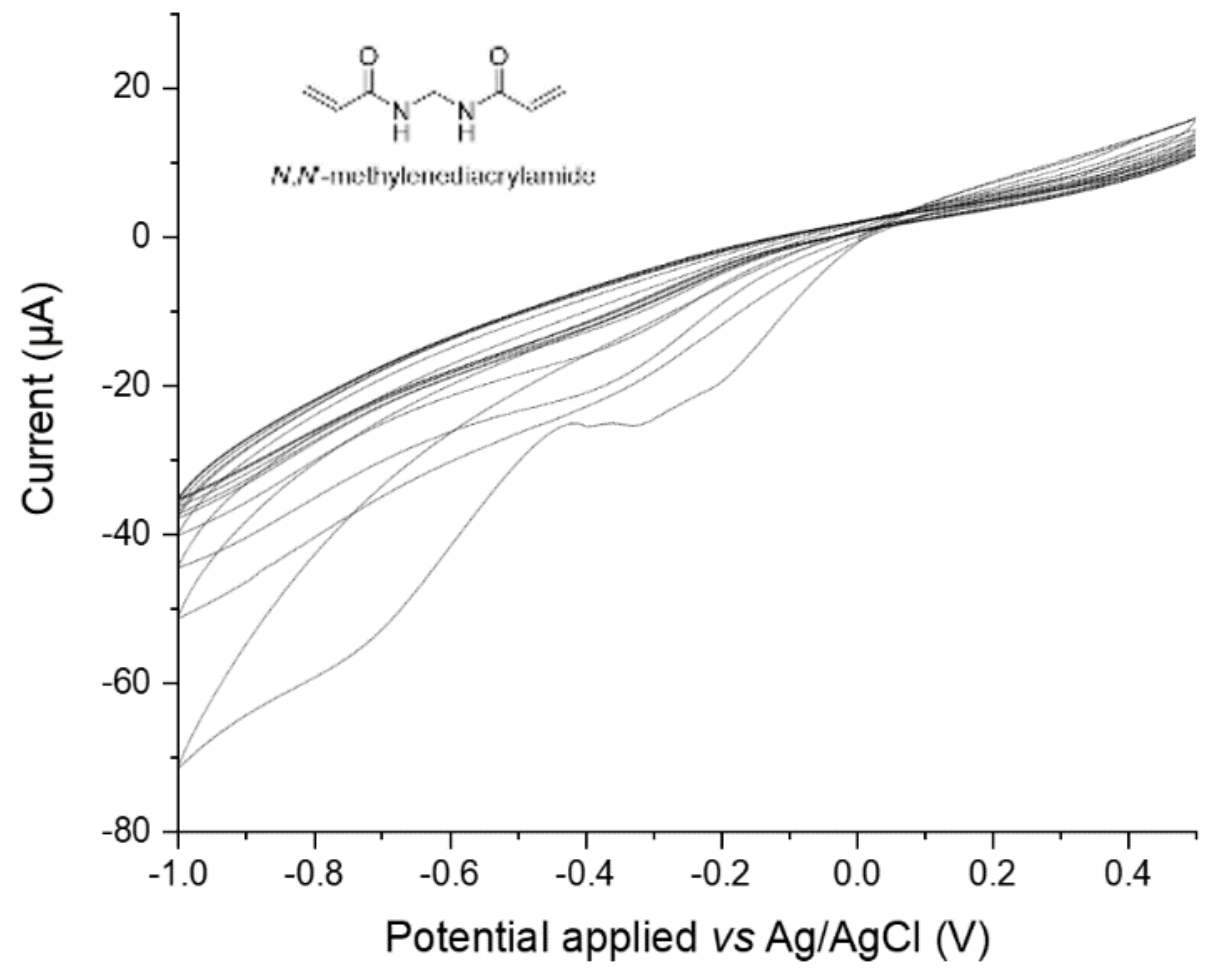




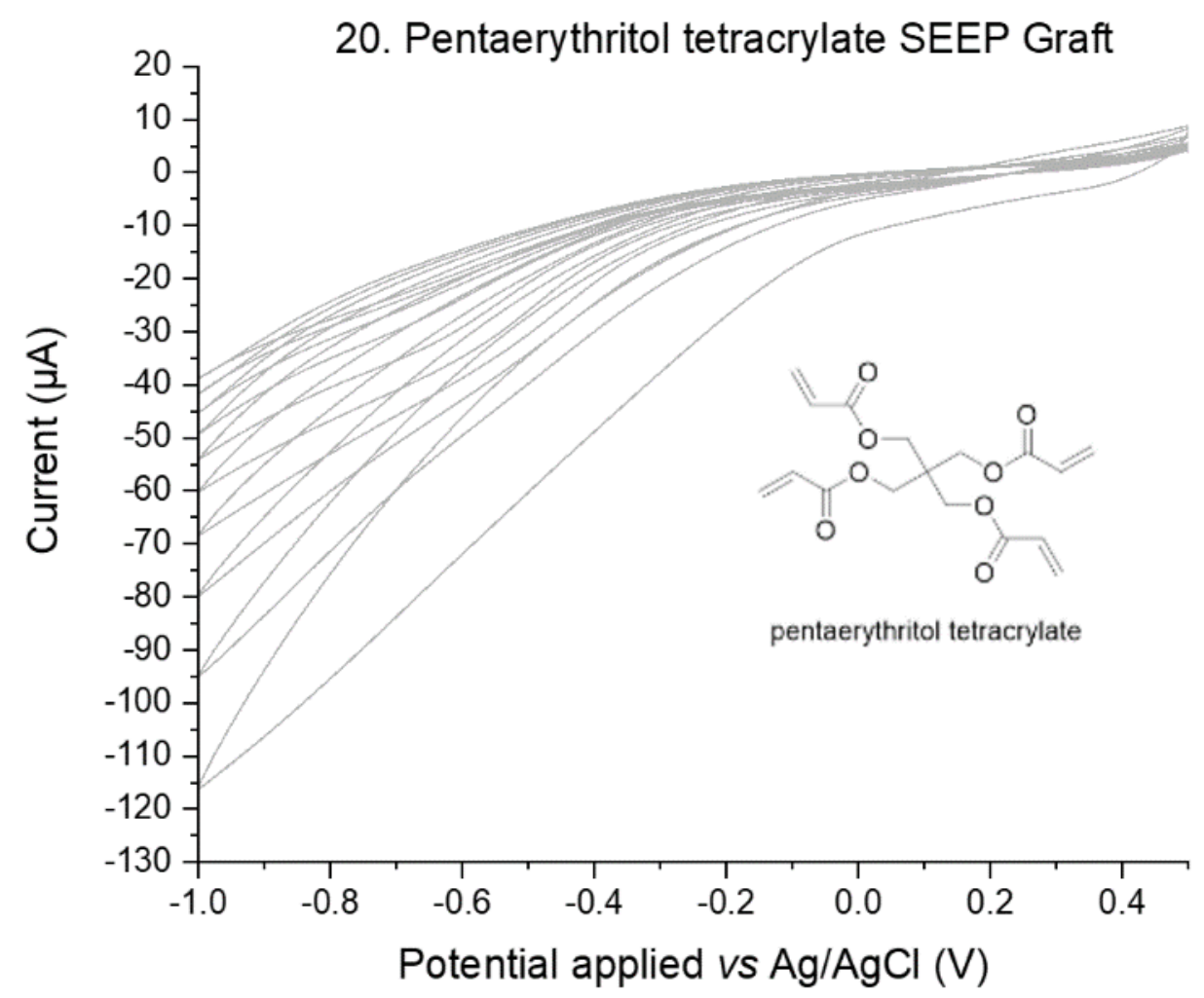


FTIR Spectra for all samples.

All spectra are overlaid from one sample with each spectrum acquired from a different location on the functionalised electrode. Monomers displayed in spectrum are inset.
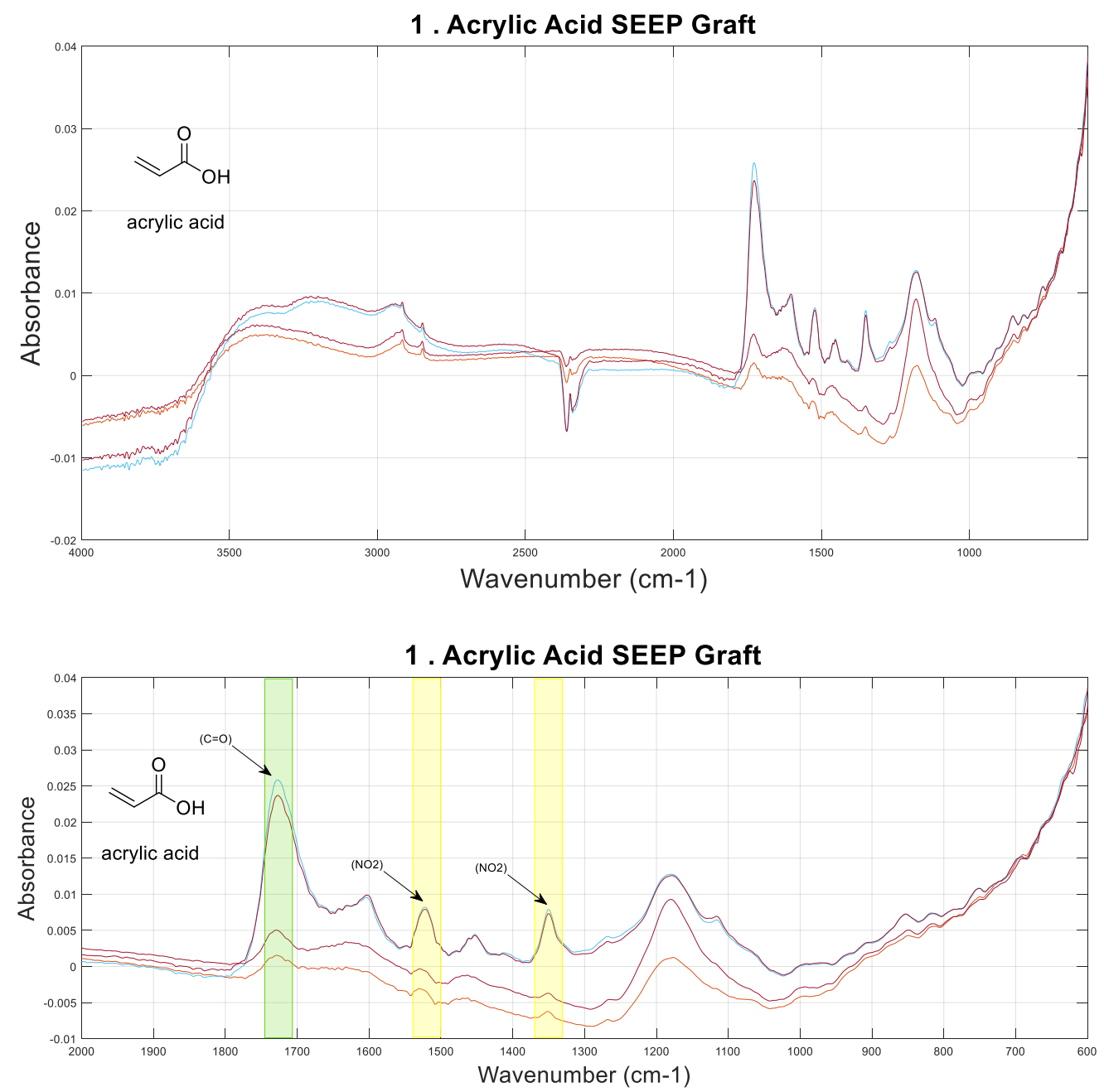
2 - Methyl Acrylate SEEP Graft

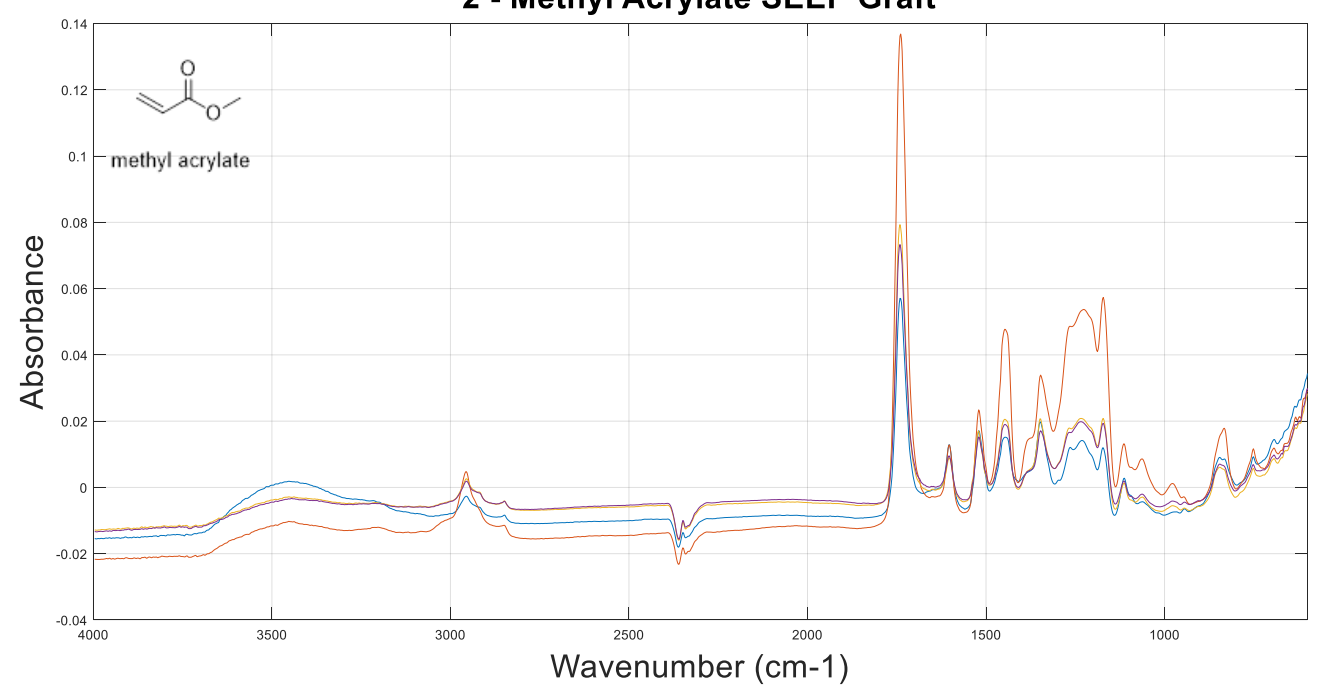

2 - Methyl Acrylate SEEP Graft

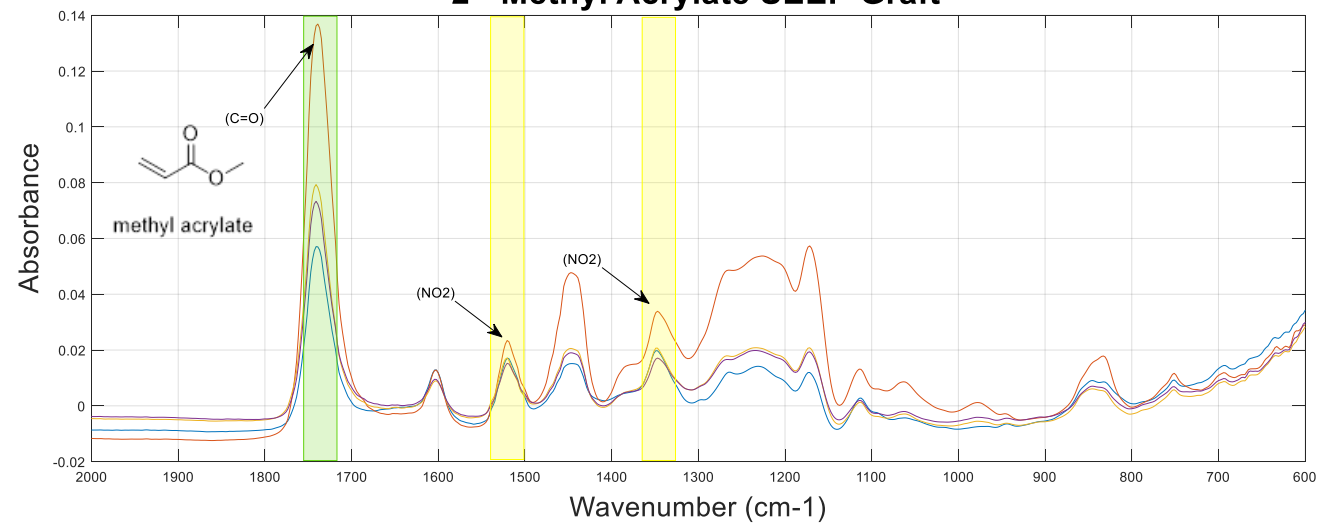


3 - Tert-butyl Acrylate SEEP Graft

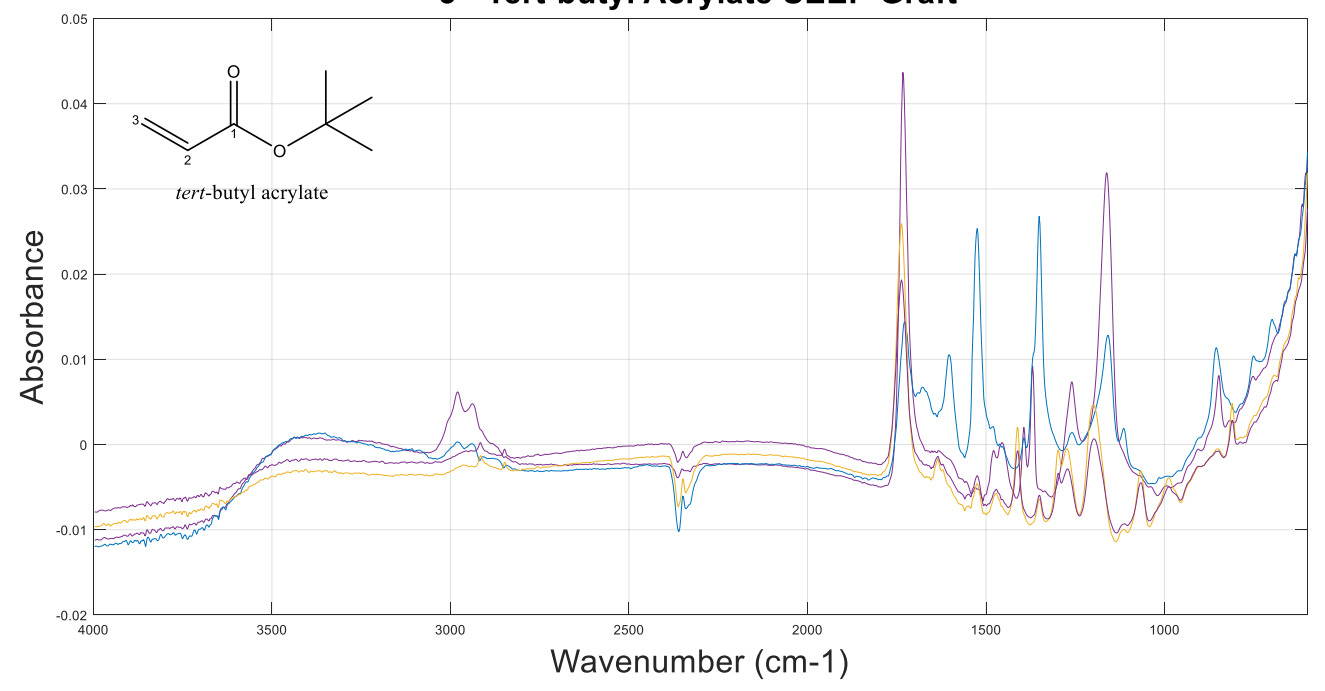

3 - Tert-butyl Acrylate SEEP Graft

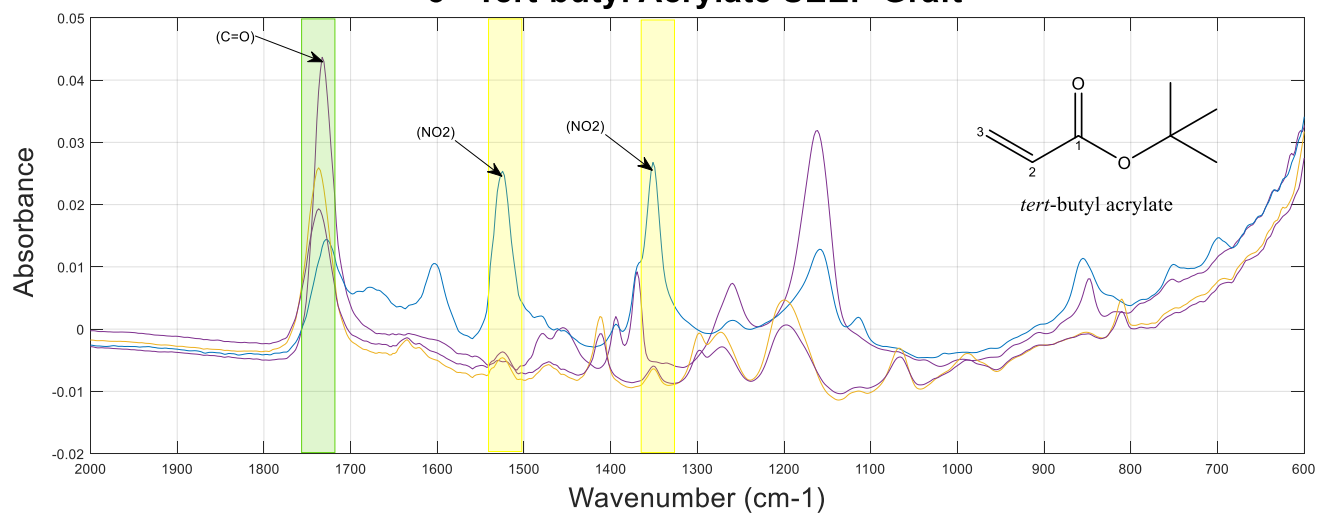



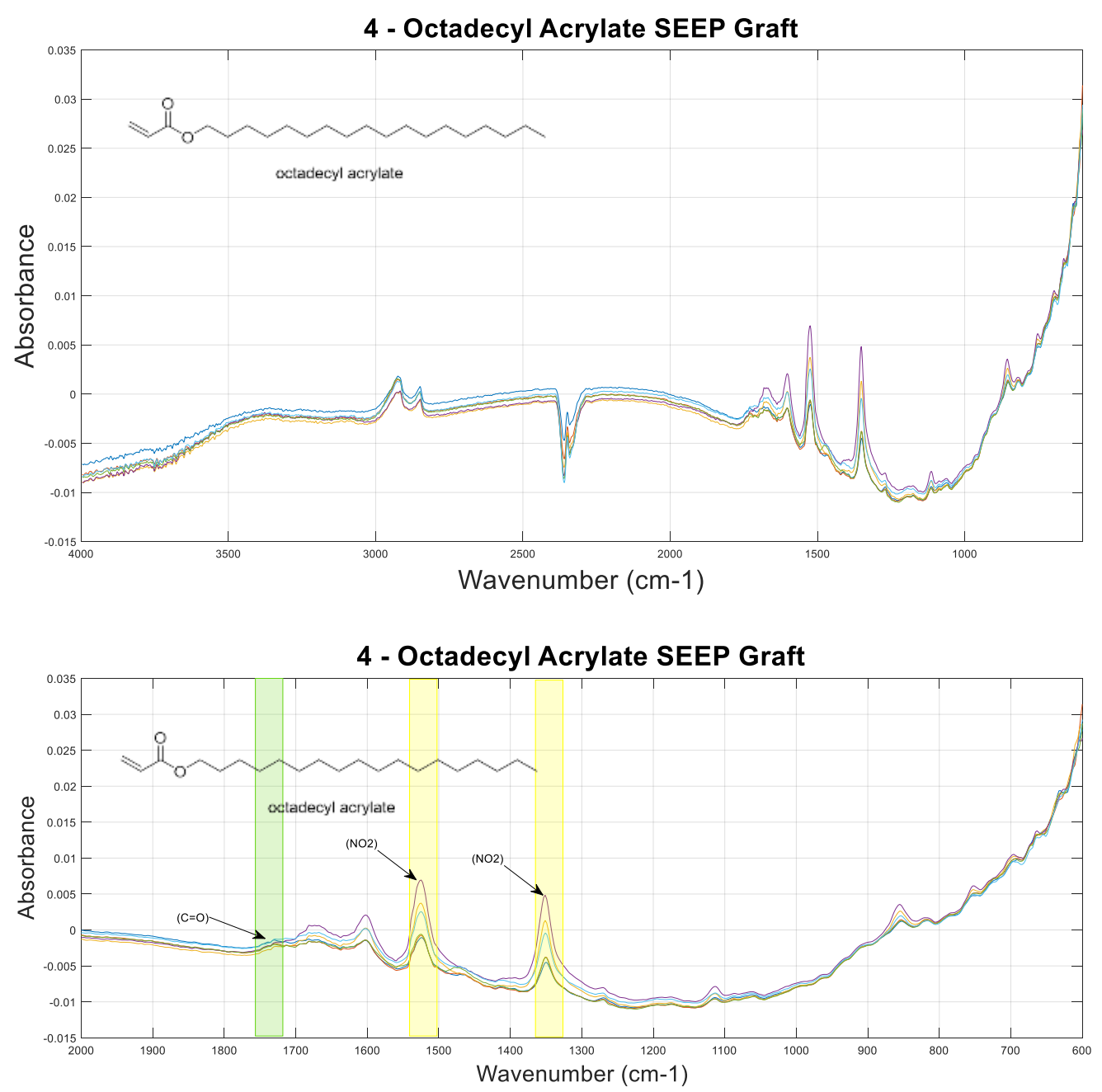

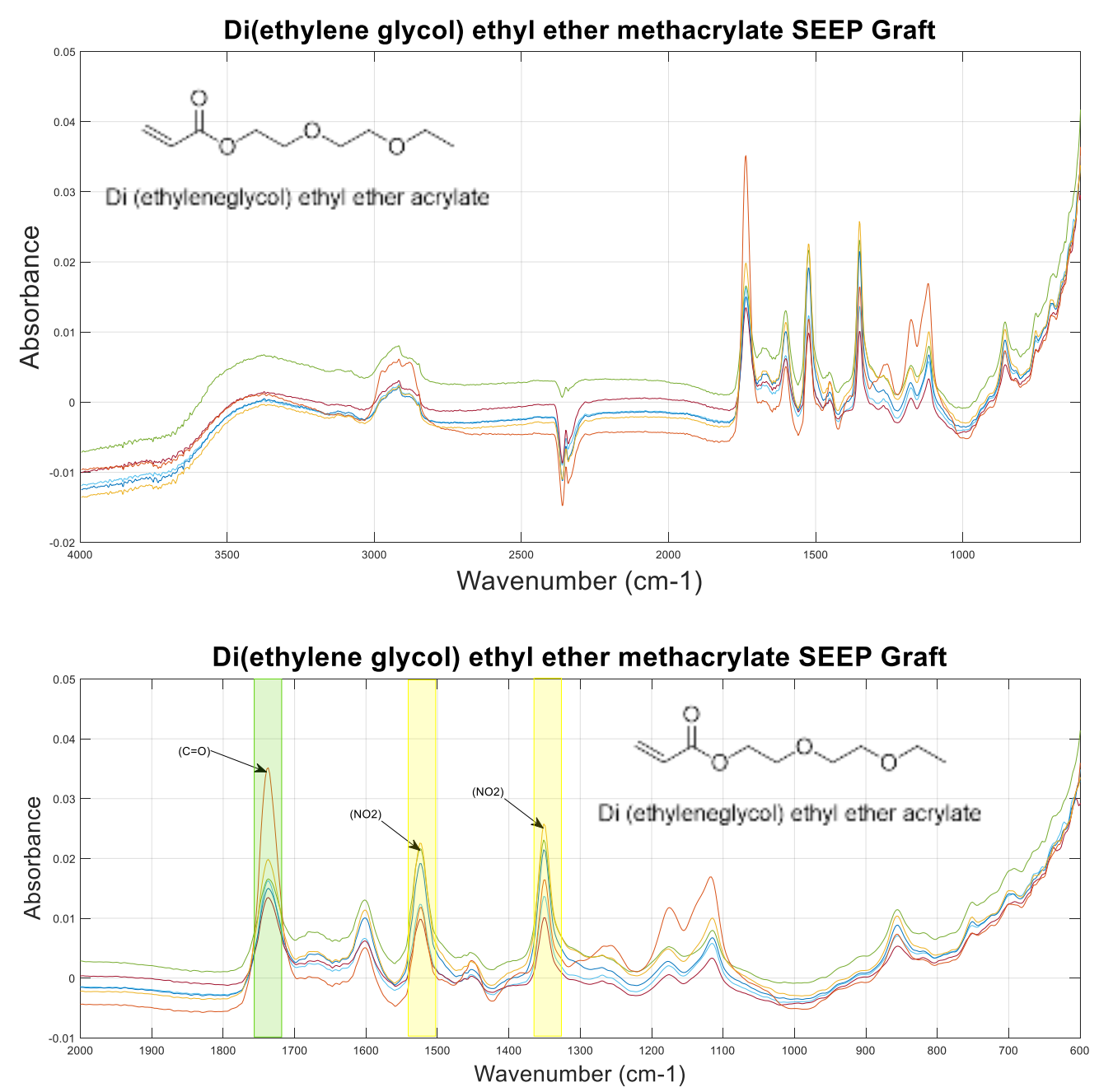

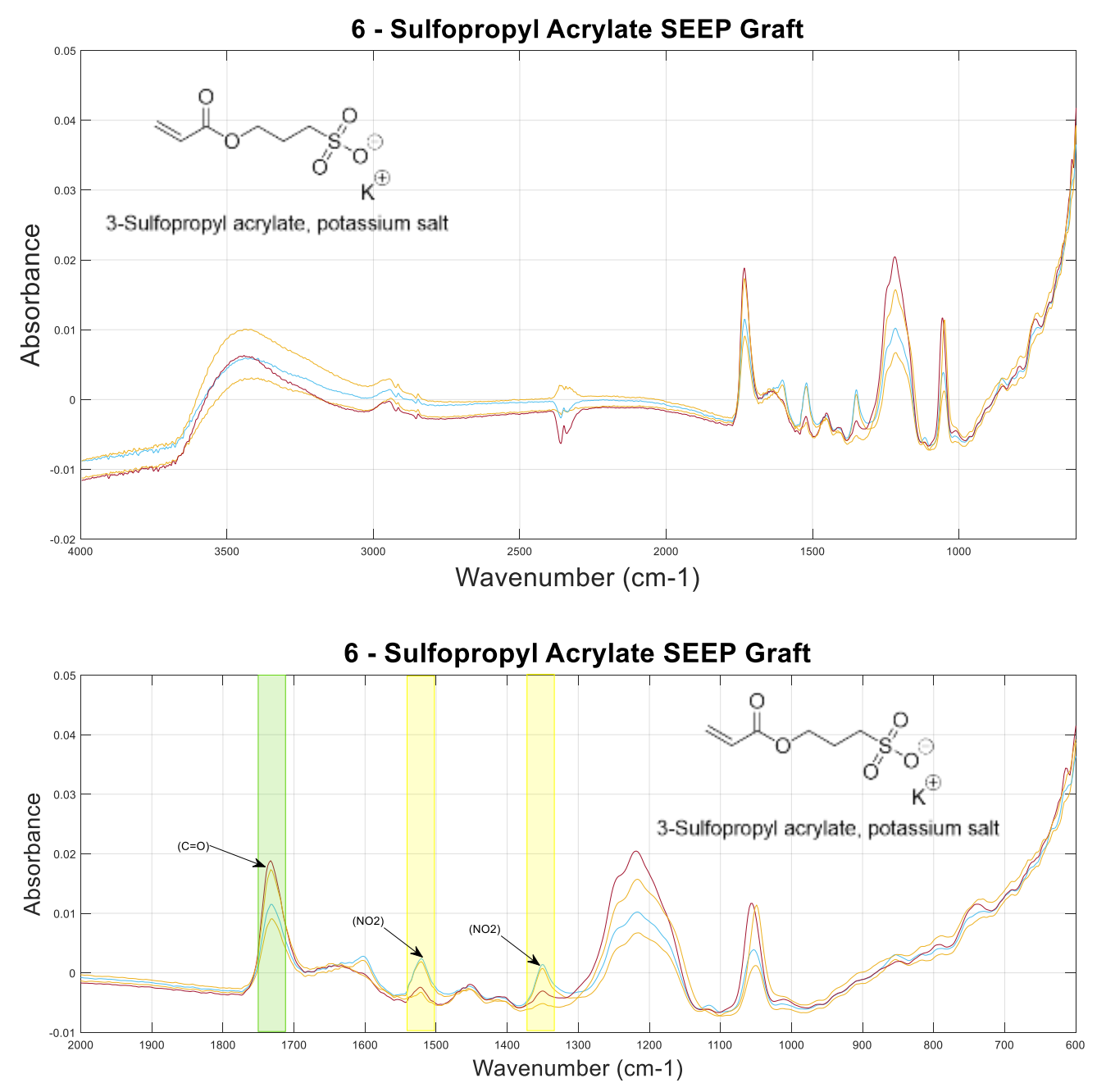
7 - Acrylamide SEEP Graft

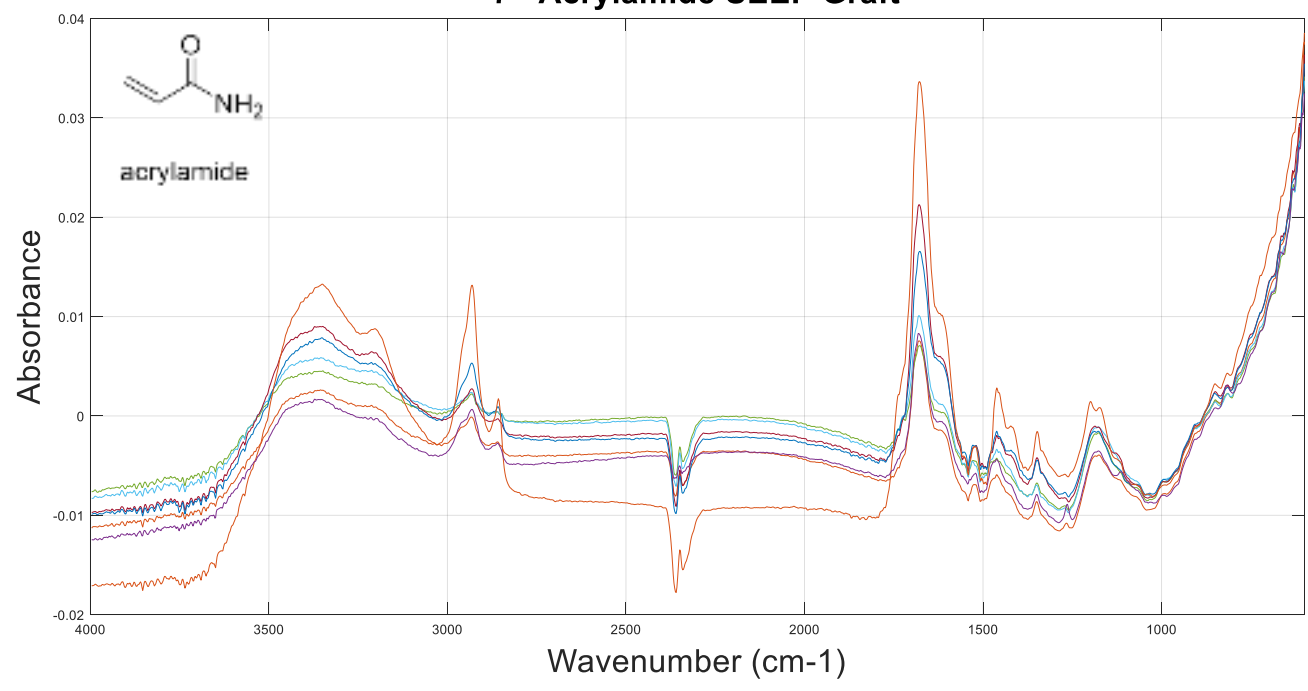

7 - Acrylamide SEEP Graft

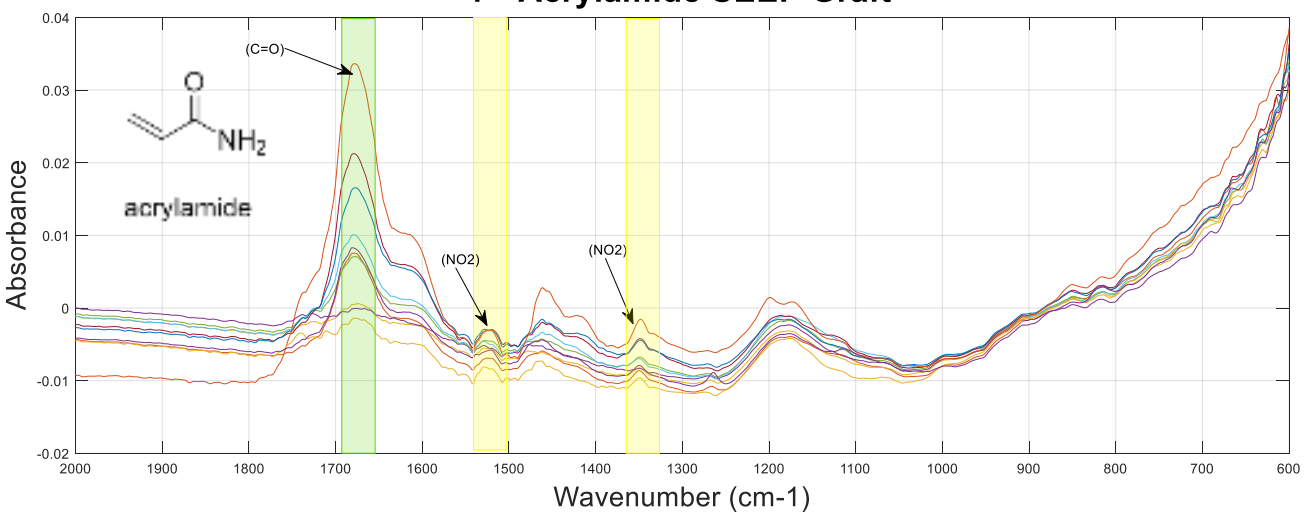



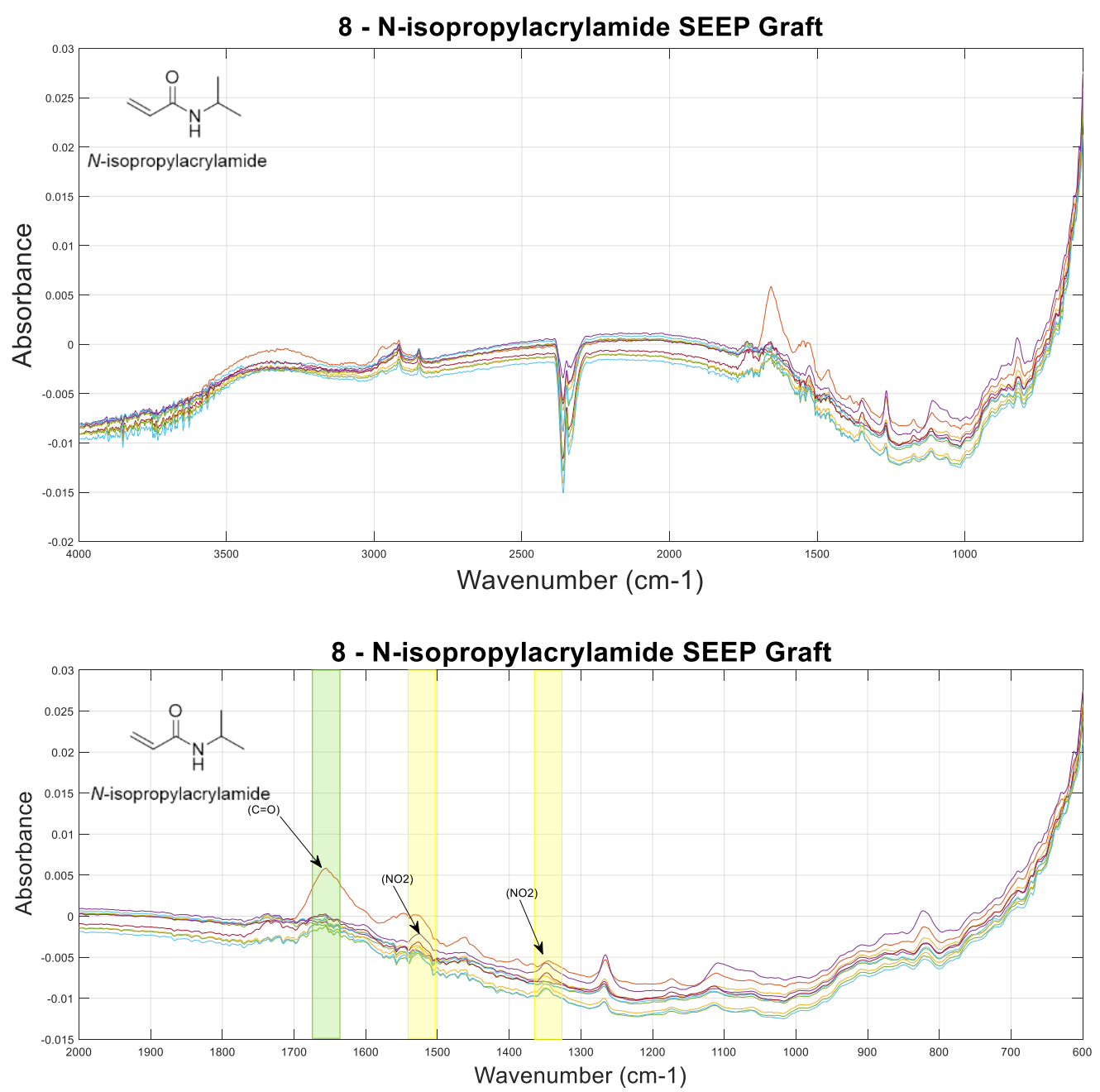
9 - Styrene SEEP Graft

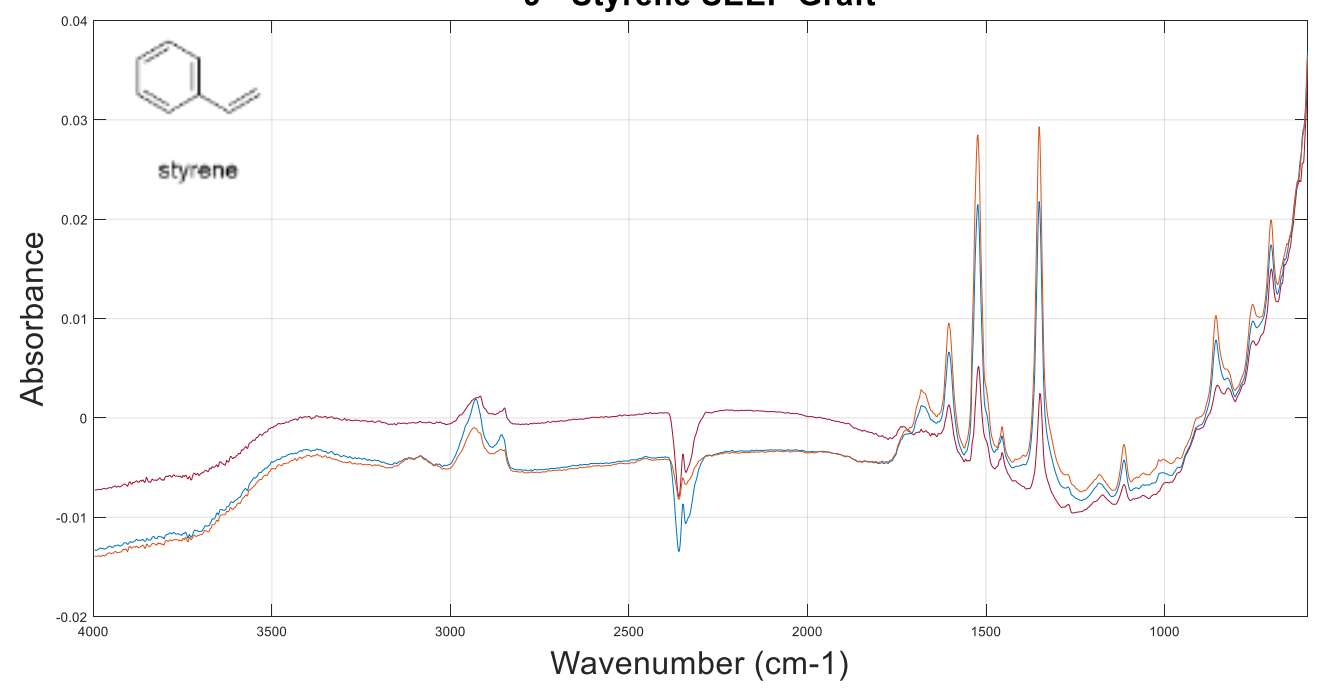

9 - Styrene SEEP Graft

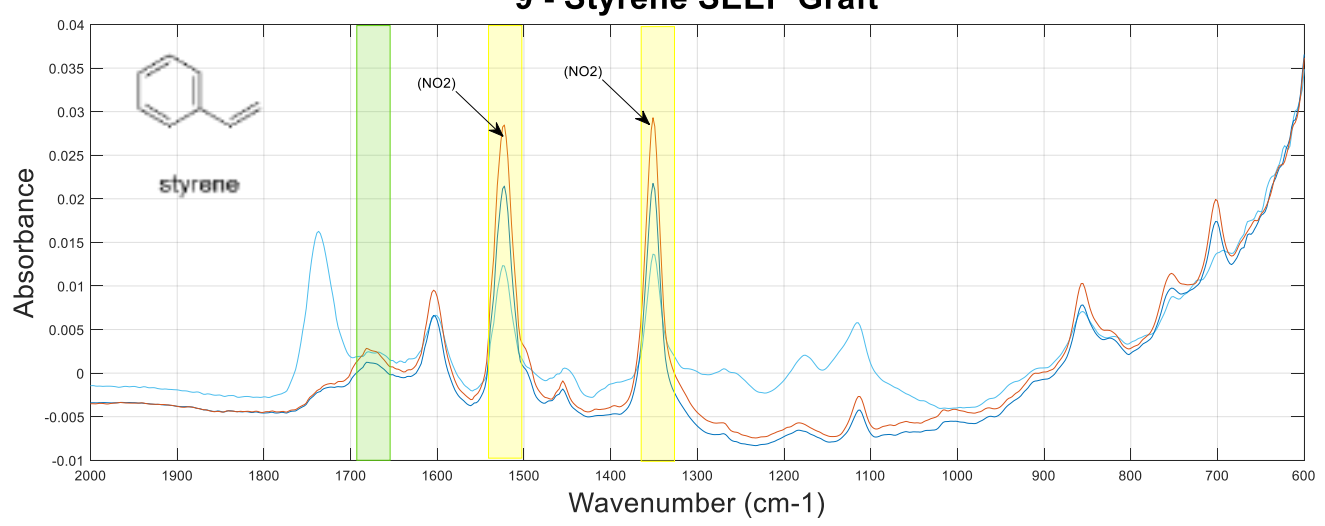


10 - Methyl Methacrylate SEEP Graft

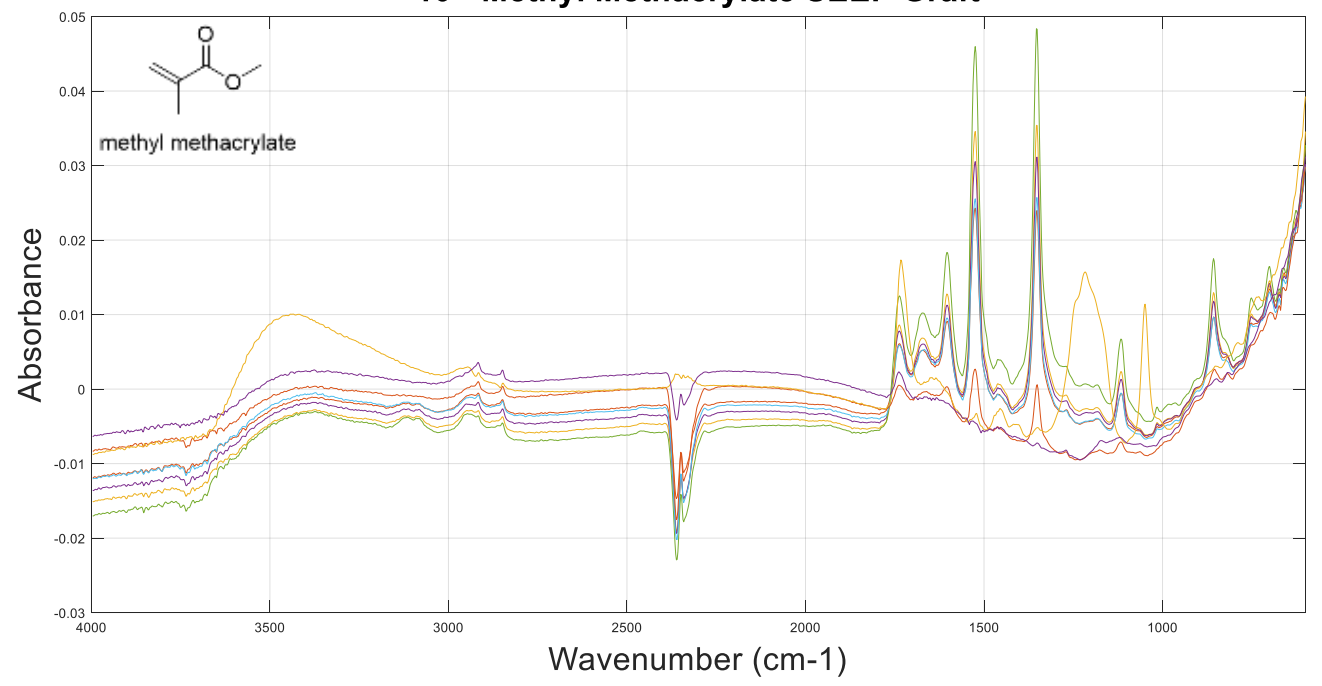

10 - Methyl Methacrylate SEEP Graft

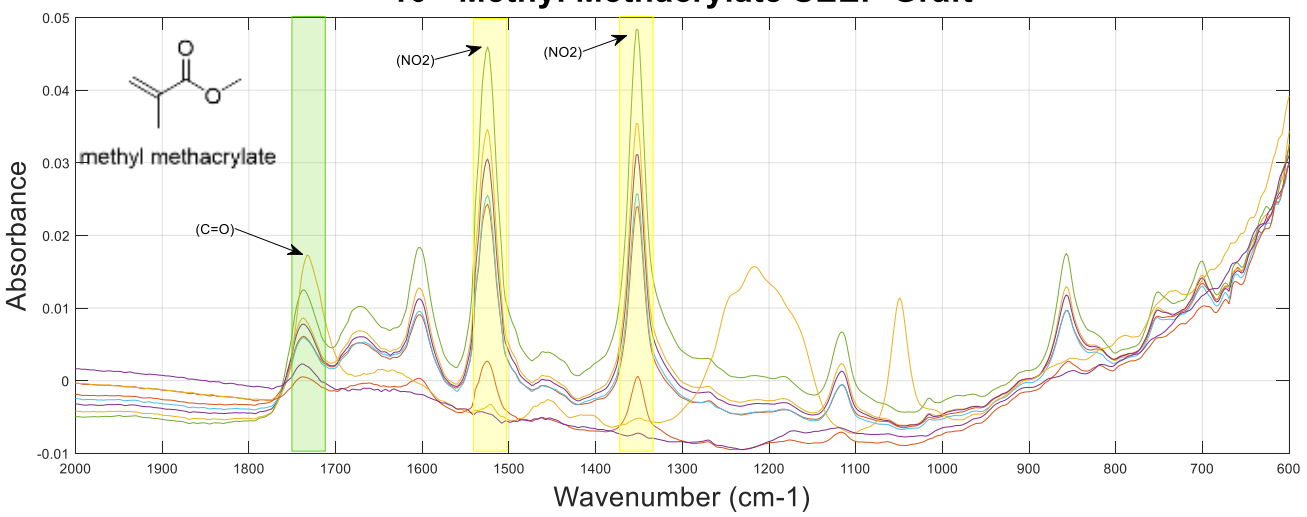



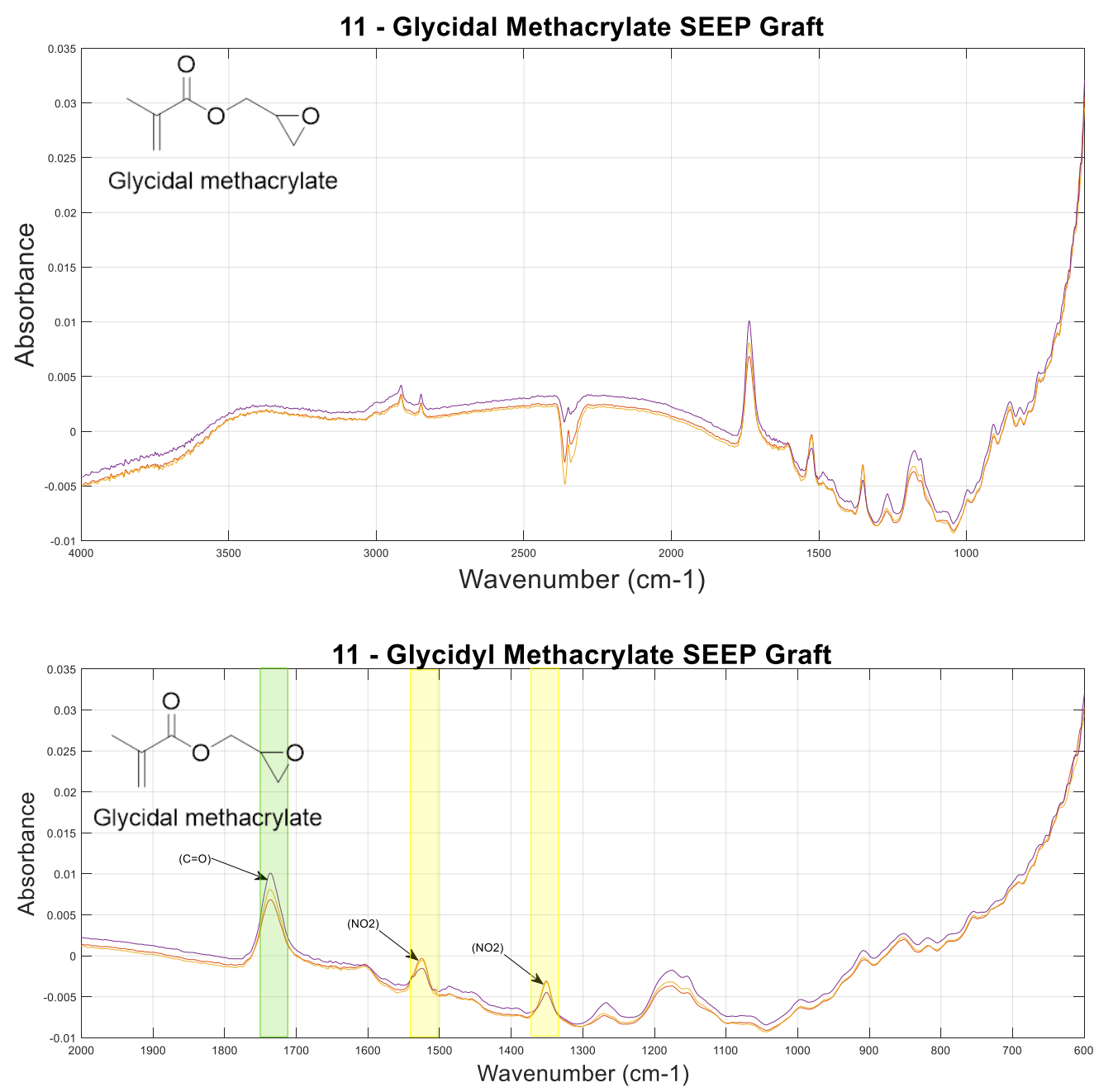
12 - Aminoethyl Methacrylate SEEP Graft

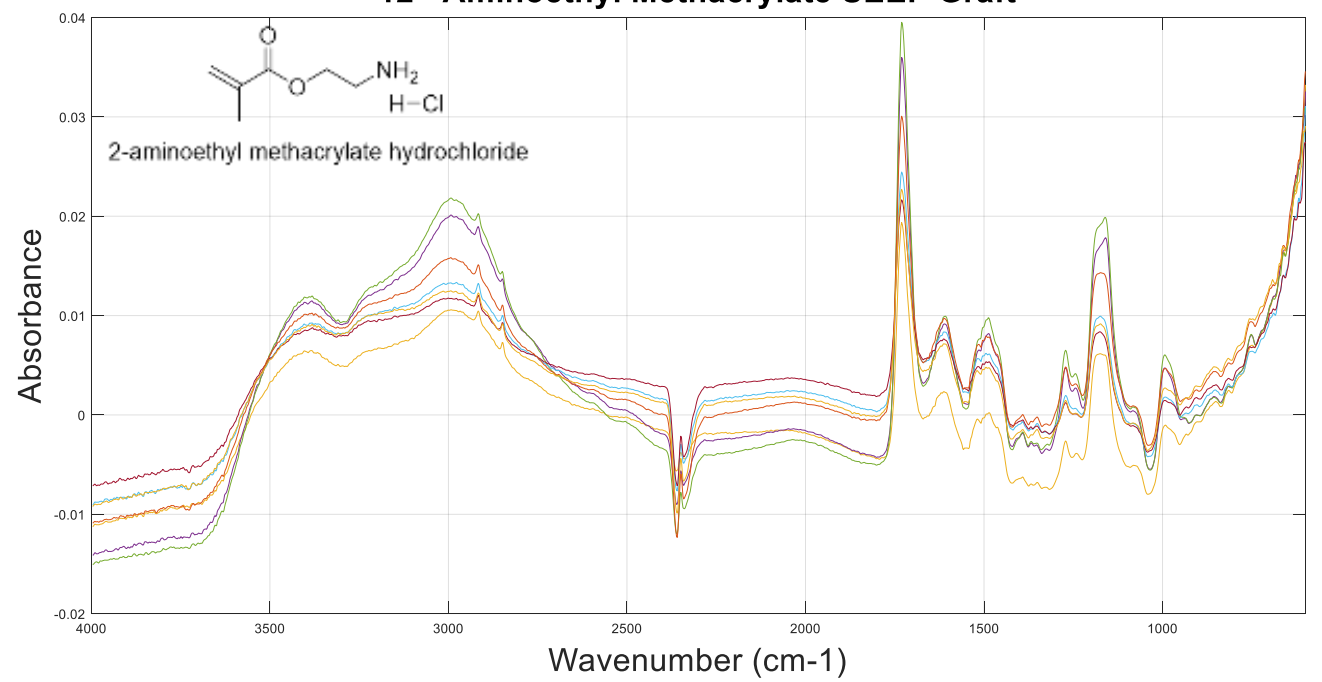

12 - Aminoethyl Methacrylate SEEP Graft

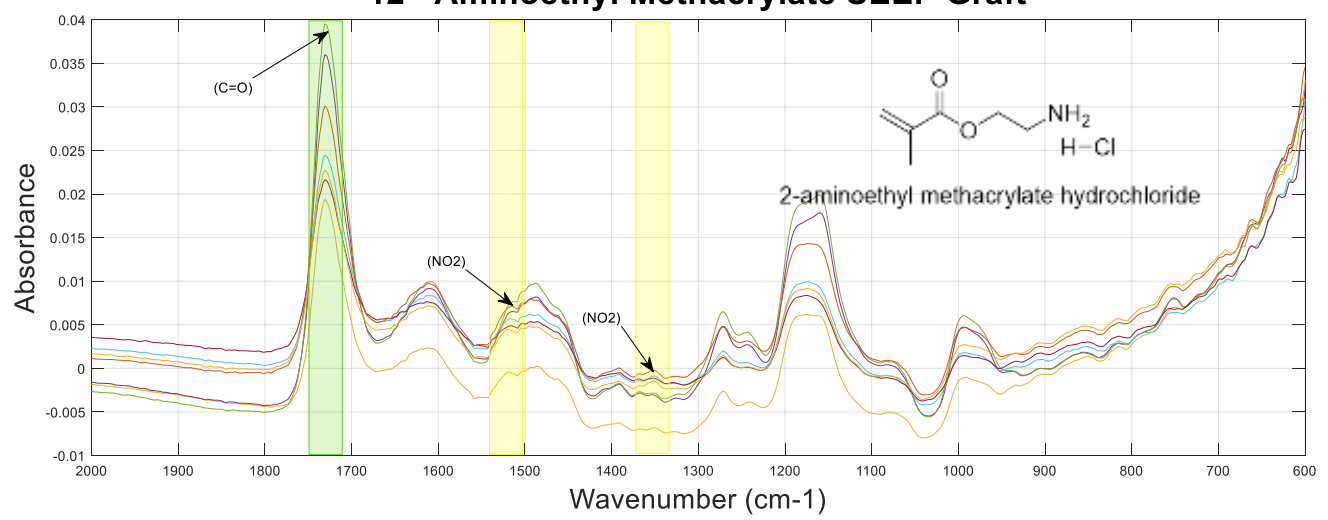




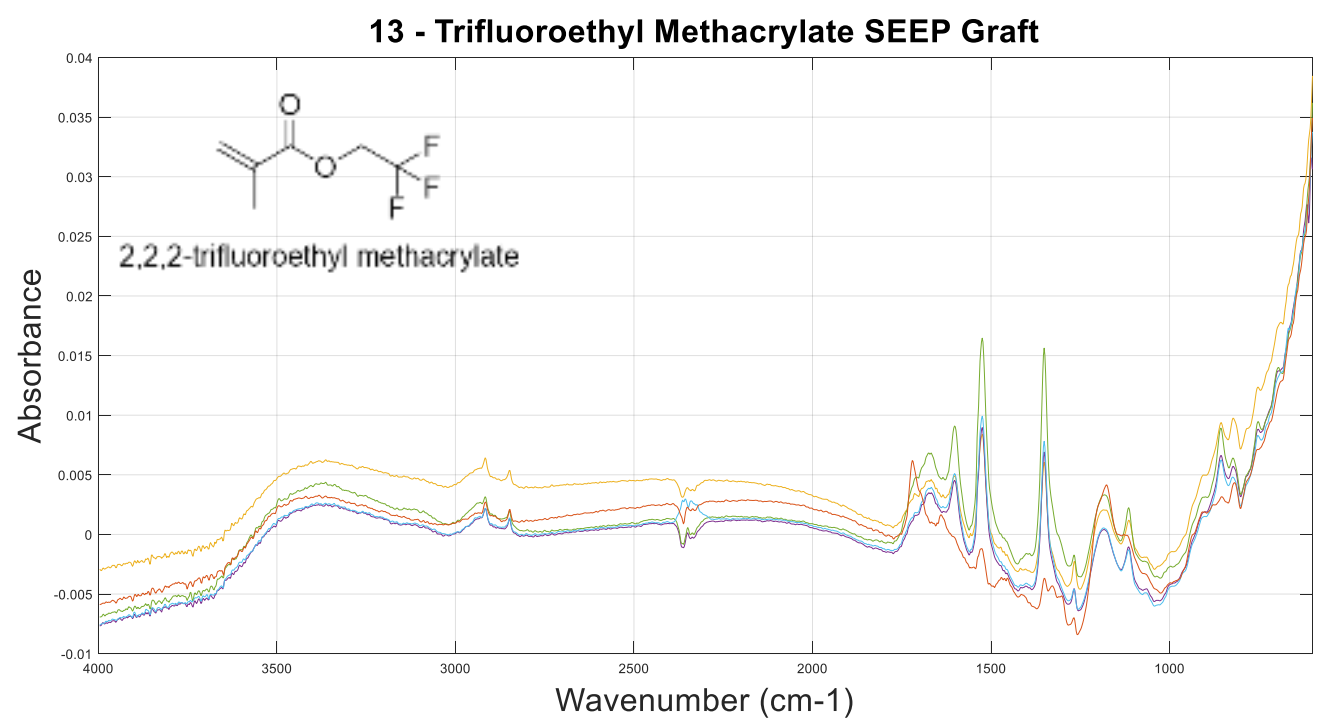

13 - Trifluoroethyl Methacrylate SEEP Graft

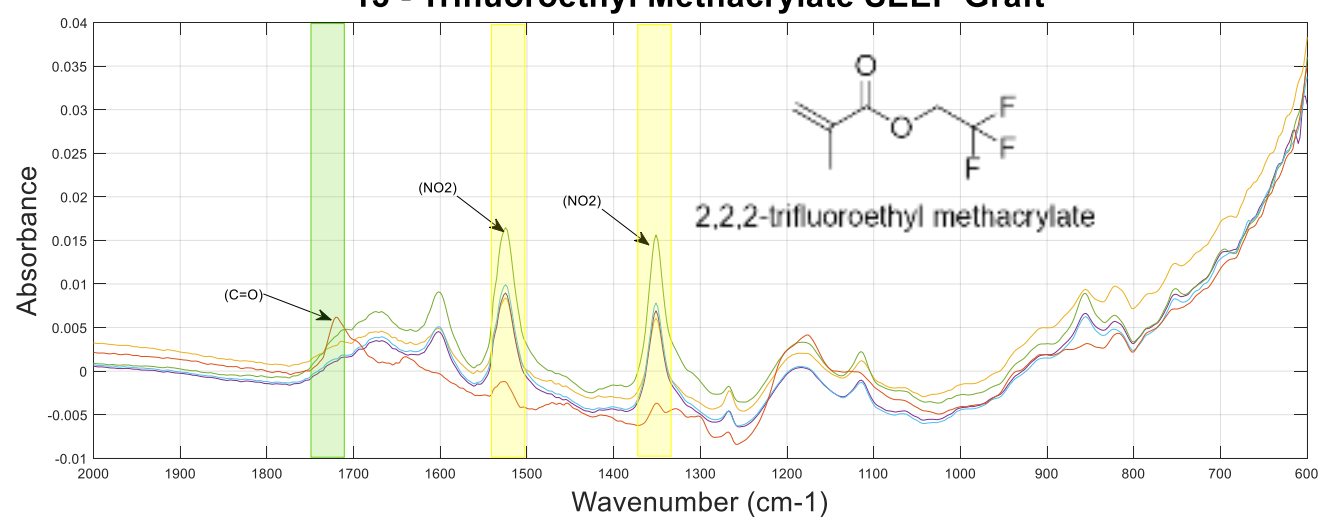



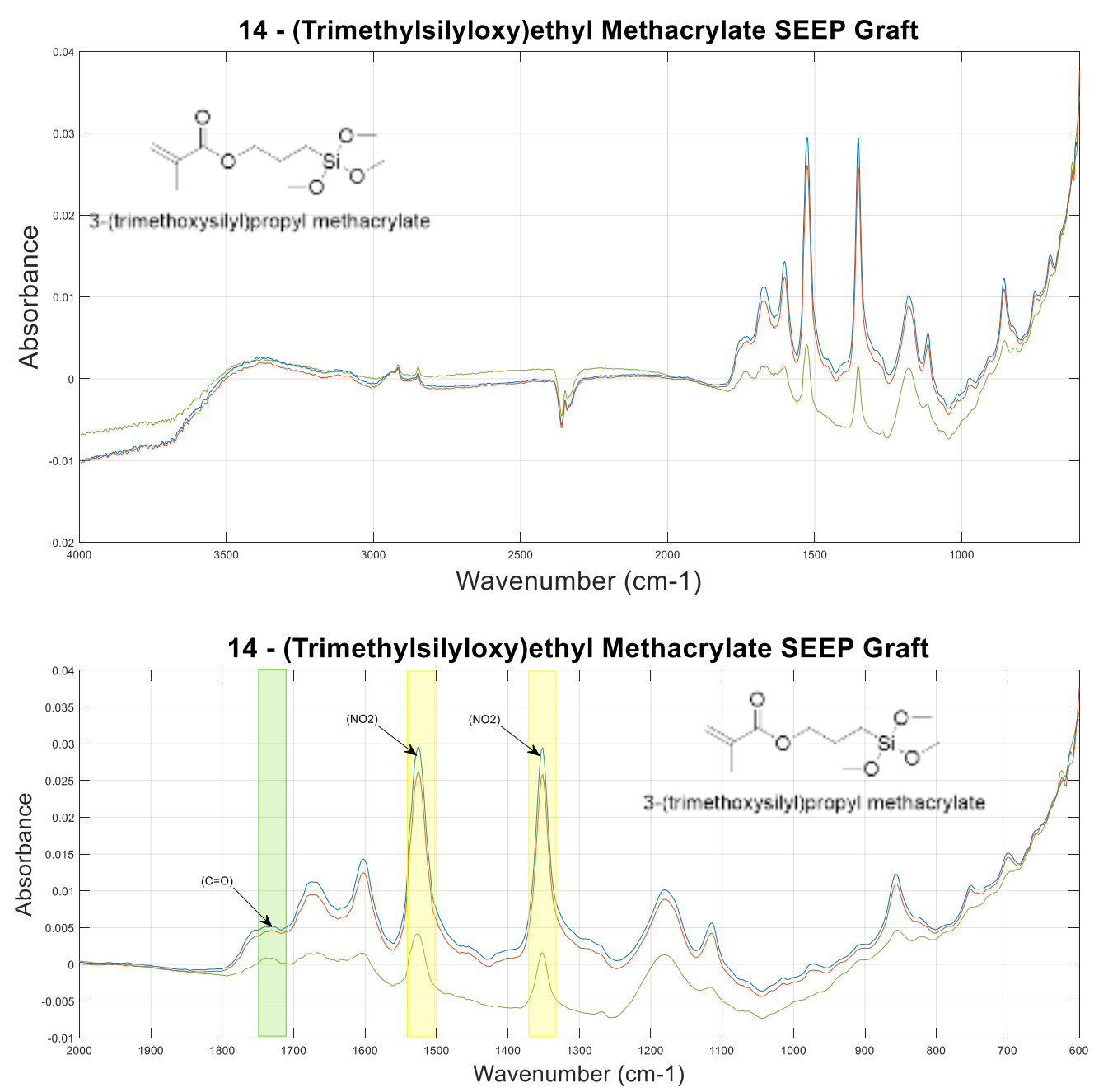
15 - Itaconic Acid SEEP Graft

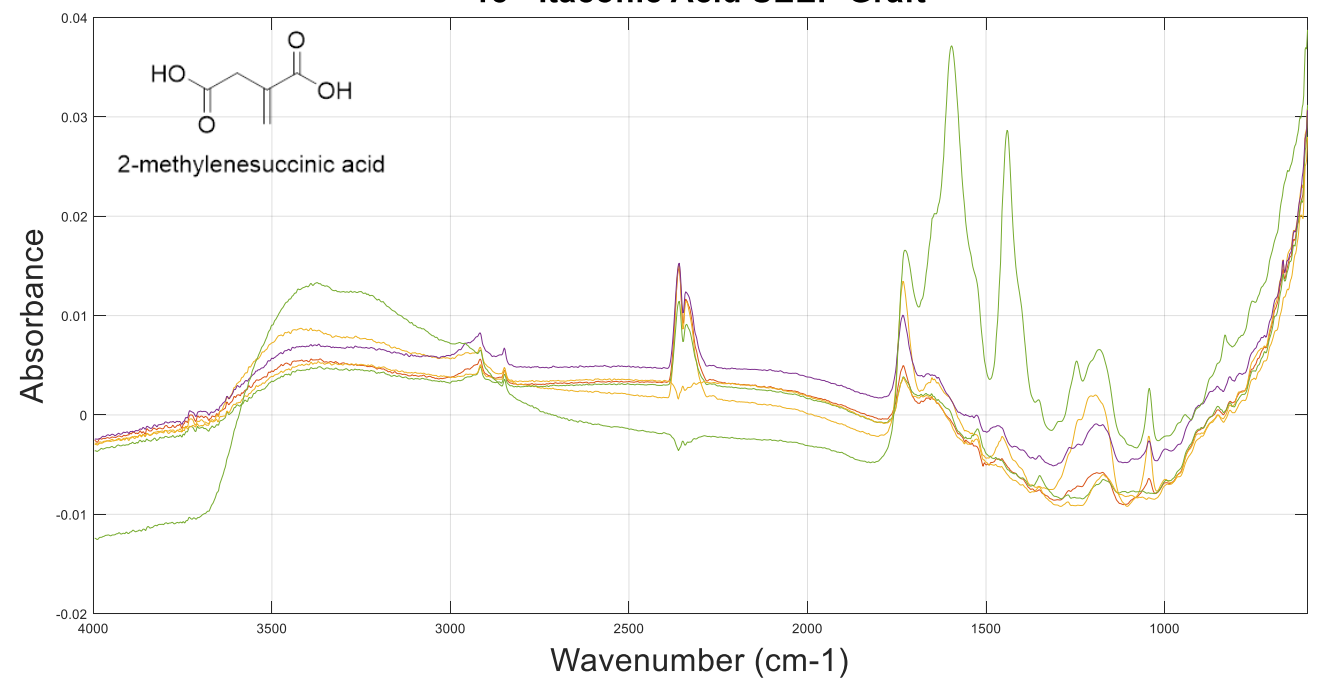

15 - Itaconic Acid SEEP Graft

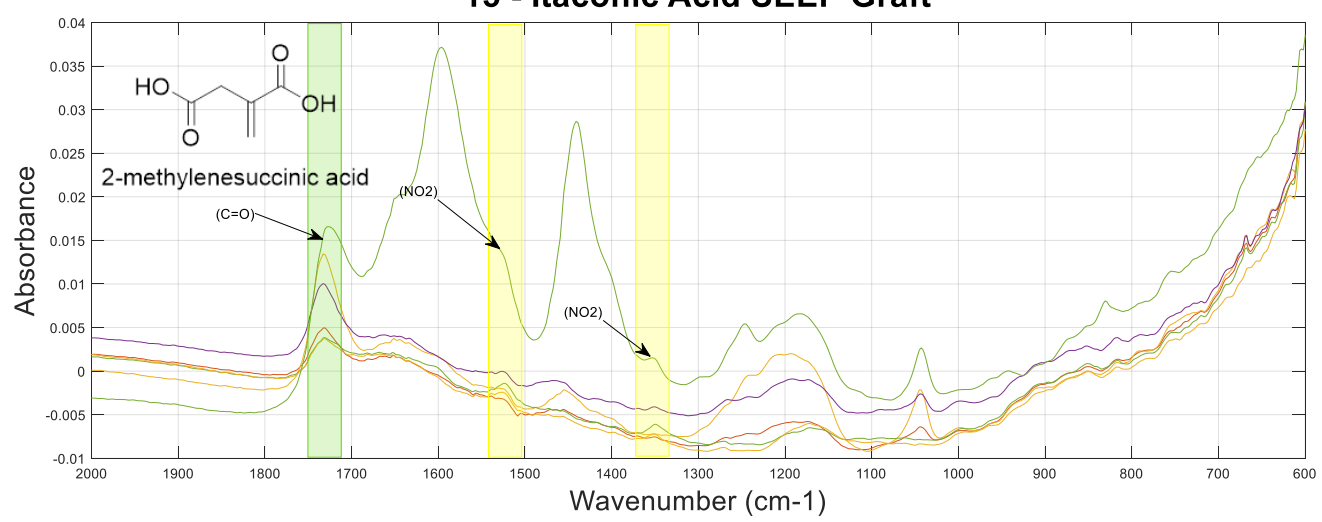



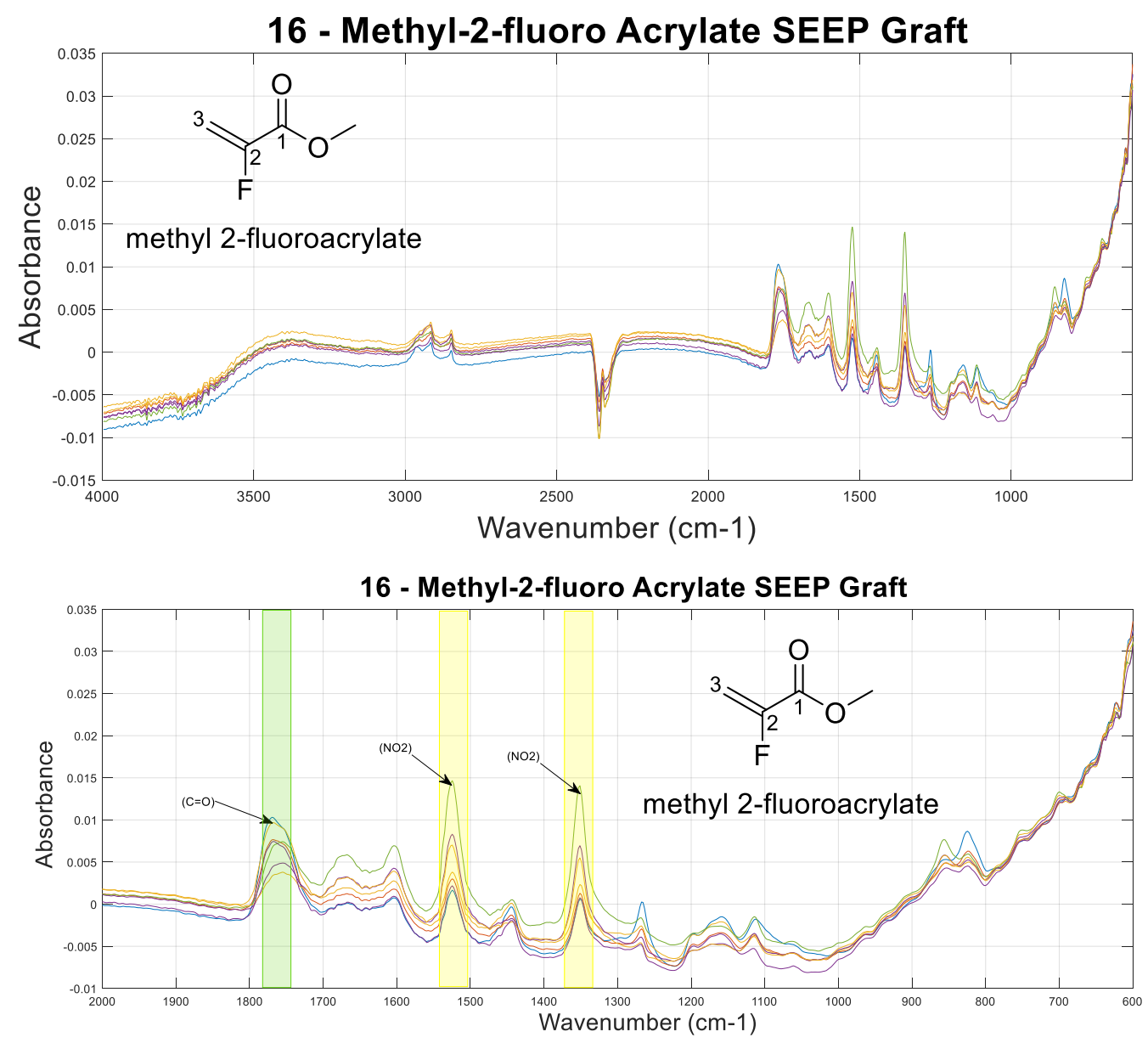

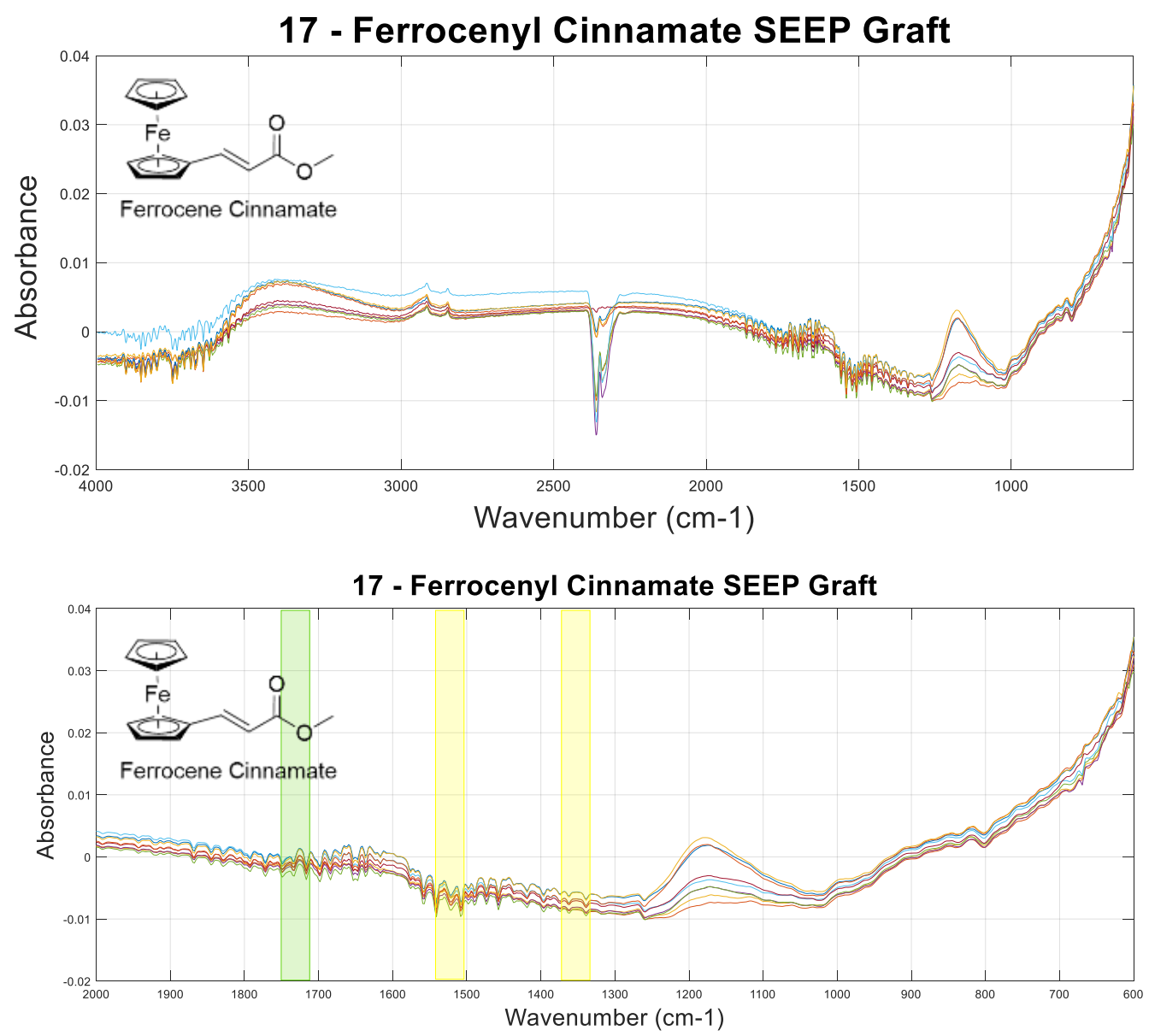


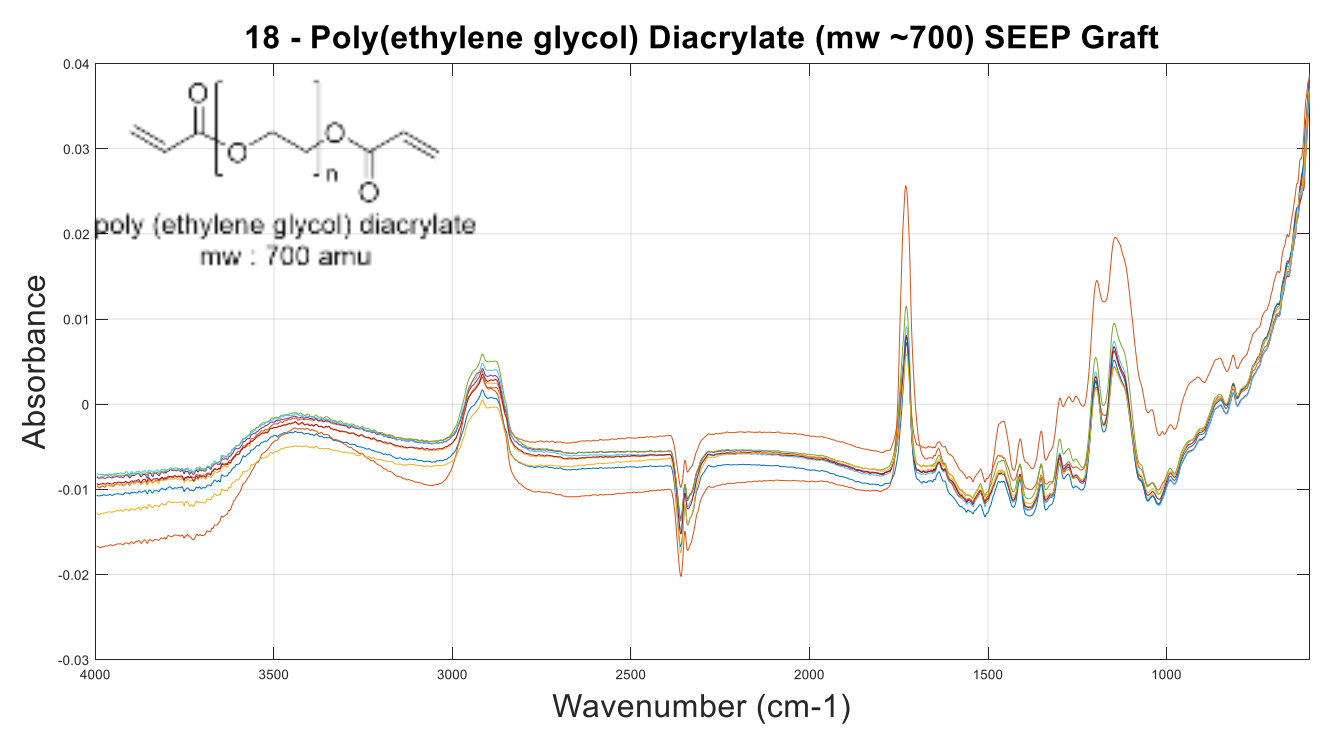

18 - Poly(ethylene glycol) Diacrylate (mw 700) SEEP Graft

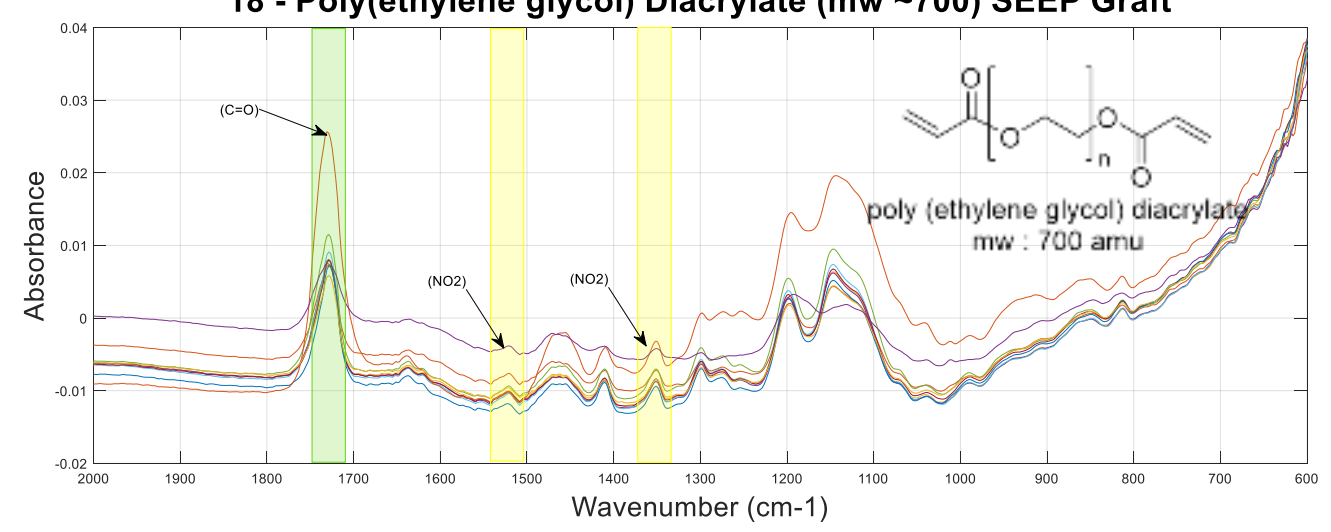




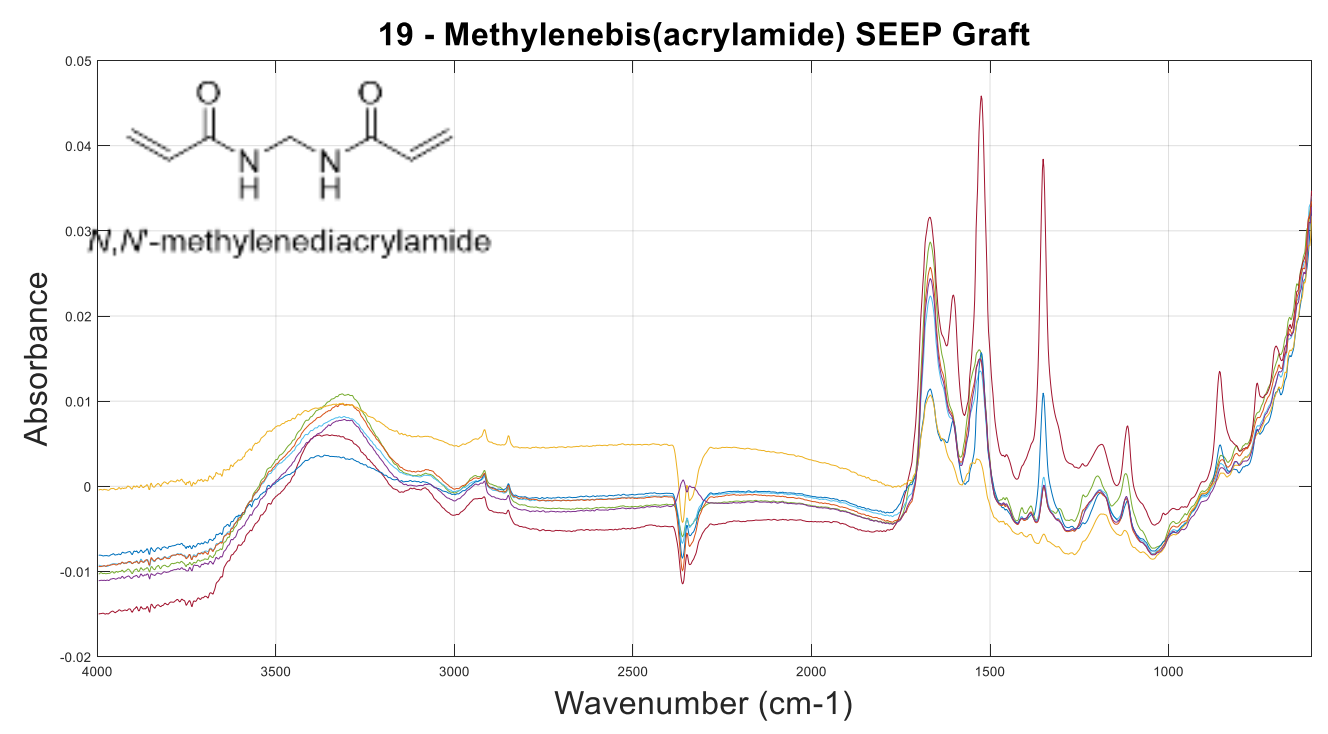

19 - Methylenebis(acrylamide) SEEP Graft

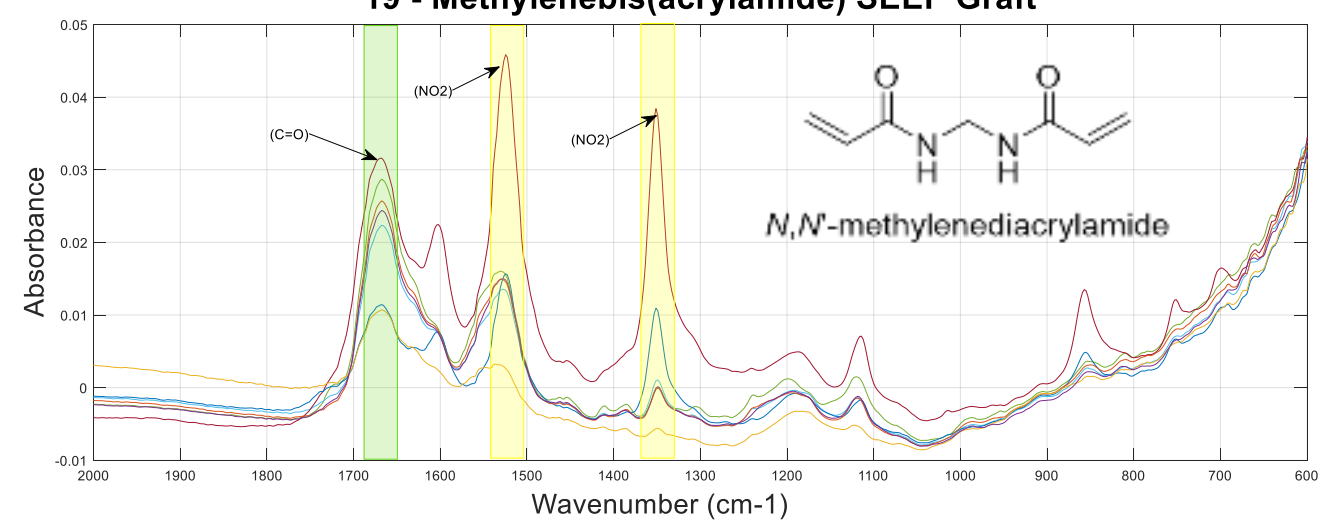



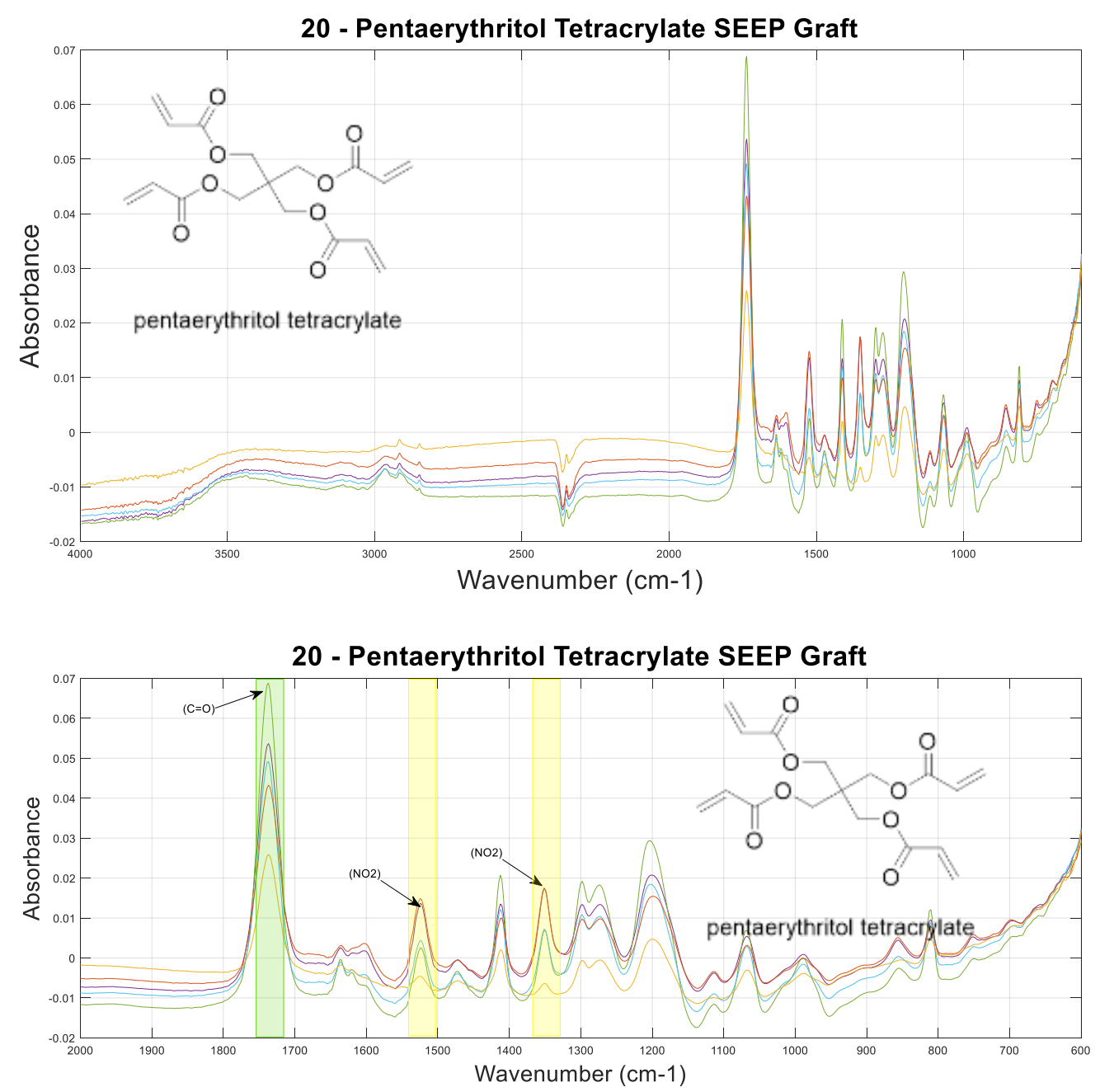


\section{Synthesis of 17}

\section{Ferrocenyl methyl cinnamate (17):}

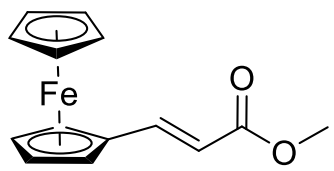

Ferrocenyl methyl cinnamate

To a solution of THF $(20 \mathrm{~mL})$ at $0{ }^{\circ} \mathrm{C}, \mathrm{NaH}(60 \%$ dispersion in oil, $600 \mathrm{mg}, 15 \mathrm{mmol})$ was added portion wise under vigorous stirring. Methyl diethylphosphonoacetate $(2755 \mu \mathrm{L}, 15 \mathrm{mmol})$ was then added dropwise. After gas evolution ceased, ferrocenecarboxaldehyde (2140 mg, $15 \mathrm{mmol})$ dissolved in THF $(10 \mathrm{~mL})$ was added dropwise and allowed to stir for 2 hours, warming to RT. Afterwards, isopropyl alcohol ( $3 \mathrm{~mL}$ ) was added to quench any remaining $\mathrm{NaH}$, followed by $\mathrm{H}_{2} \mathrm{O}(10 \mathrm{~mL})$. The aqueous mixture was extracted into EtOAc $(20 \mathrm{~mL})$ and washed with $\mathrm{H}_{2} \mathrm{O}(2 \times 10 \mathrm{~mL})$, and saturated $\mathrm{NaCl}(2$ $\mathrm{x} 10 \mathrm{~mL}$ ). The organic mixture was then dried with $\mathrm{MgSO}_{4}$, and the solvent removed under reduced pressure to yield the product as a crimson crystalline solid $(2.70 \mathrm{~g}, 99 \%)$.

${ }^{1} \mathrm{H}\left(\mathrm{CDCl}_{3}, 400 \mathrm{MHz}\right): \delta 3.76$ (s, 3H, CH3), 4.14 (s, 5H, Fc), 4.39 (t, 2H, J = 2.8 Hz, Fc), 4.48 (t, 2H, J $=2.8 \mathrm{~Hz}, \mathrm{Fc}), 6.03(\mathrm{~d}, 1 \mathrm{H}, \mathrm{J}=15.6 \mathrm{~Hz}, 2-\mathrm{H}), 7.57(\mathrm{~d}, 1 \mathrm{H}, \mathrm{J}=15.6 \mathrm{~Hz}, 3-\mathrm{H})$. Matched literature value. ${ }^{1}$

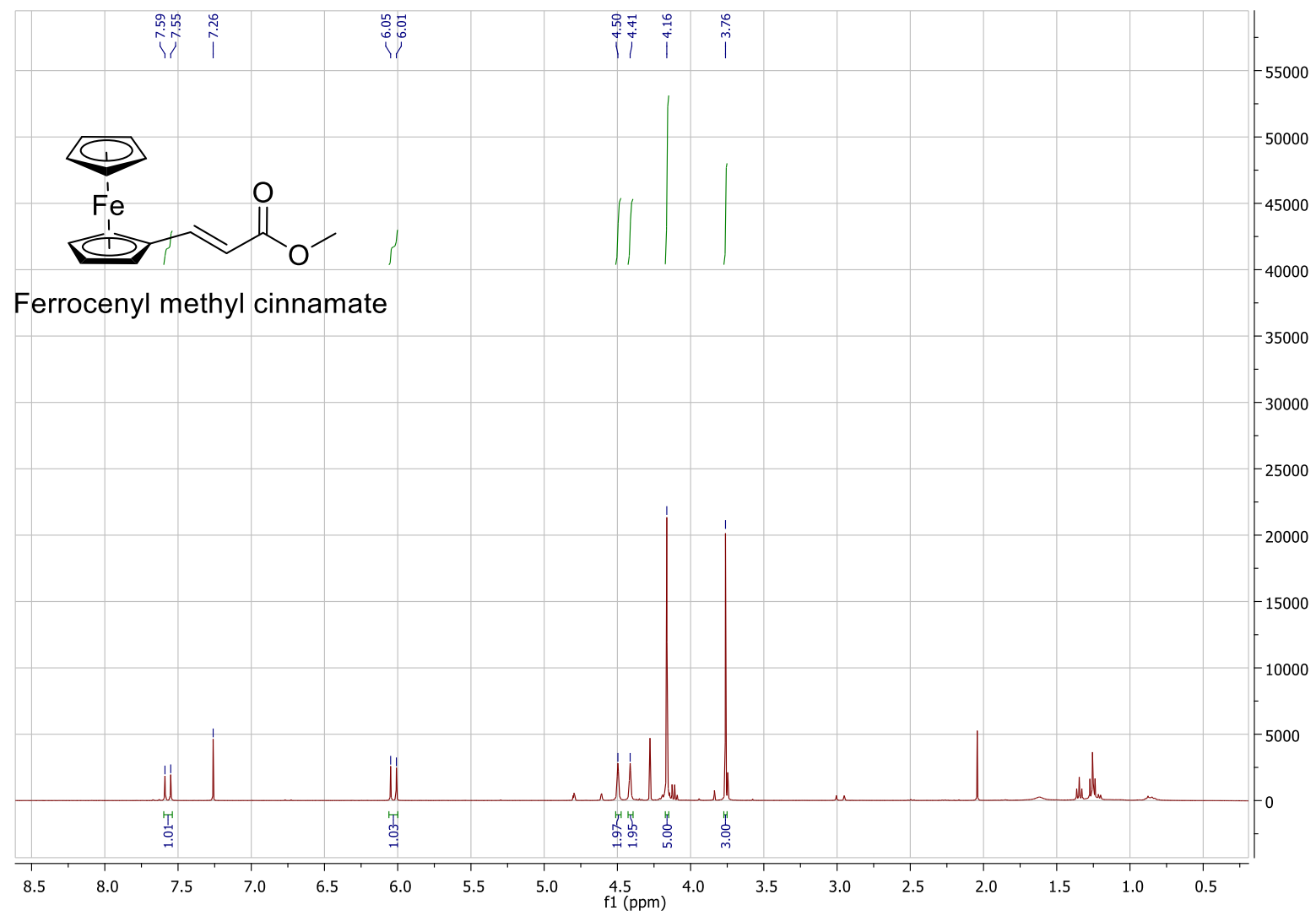


XPS spectra and elemental information for electrodes modified with monomers 6,13 , and 14<smiles>C=CC(=O)OCCCS(=O)(=O)O[Na]</smiles>
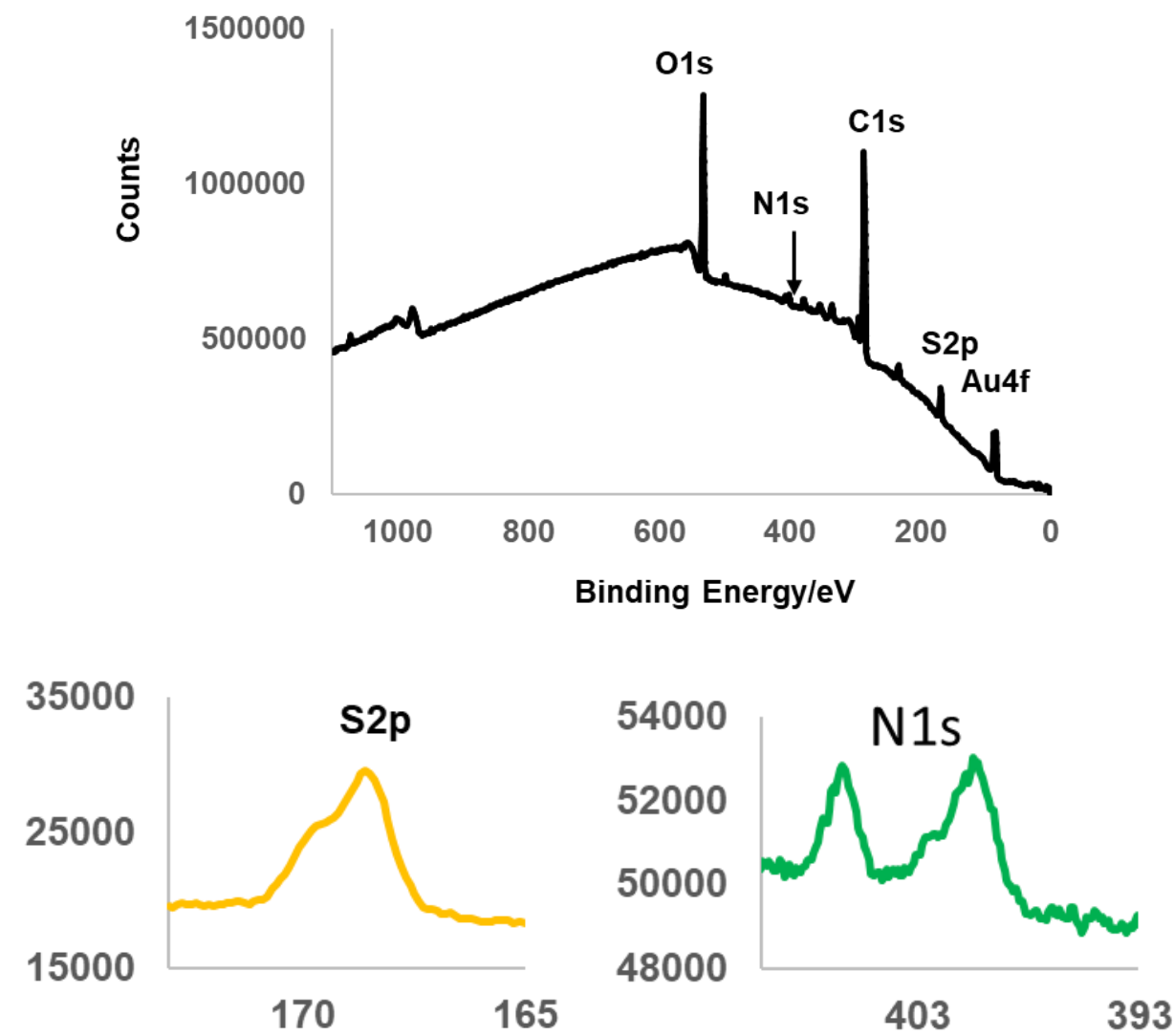

\begin{tabular}{cccc}
\hline Acrylate 6 & Binding Energy $(\mathrm{eV})$ & Atomic \% & Assignment \\
\hline Au4f & 84.4 & 1.0 & Substrate \\
C1s & 285.6 & 54.5 & $\mathbf{C}-\mathrm{C}, \mathbf{C H}$ \\
C1s A & 287.2 & 6.5 & \\
C1SB & 289.5 & 4.7 & $-\mathbf{N}=\mathbf{N}-$, \\
N1s A & 400.4 & 2.2 & NO2 \\
N1s B & 406.5 & 1.1 & All oxygens \\
O1s & 532.5 & 27.3 & Oxidized Sulfur \\
S2p & 168.7 & 4.3 & Contamination \\
Si2p & 102.5 & 0.5 &
\end{tabular}




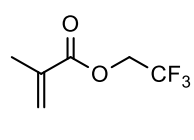

13

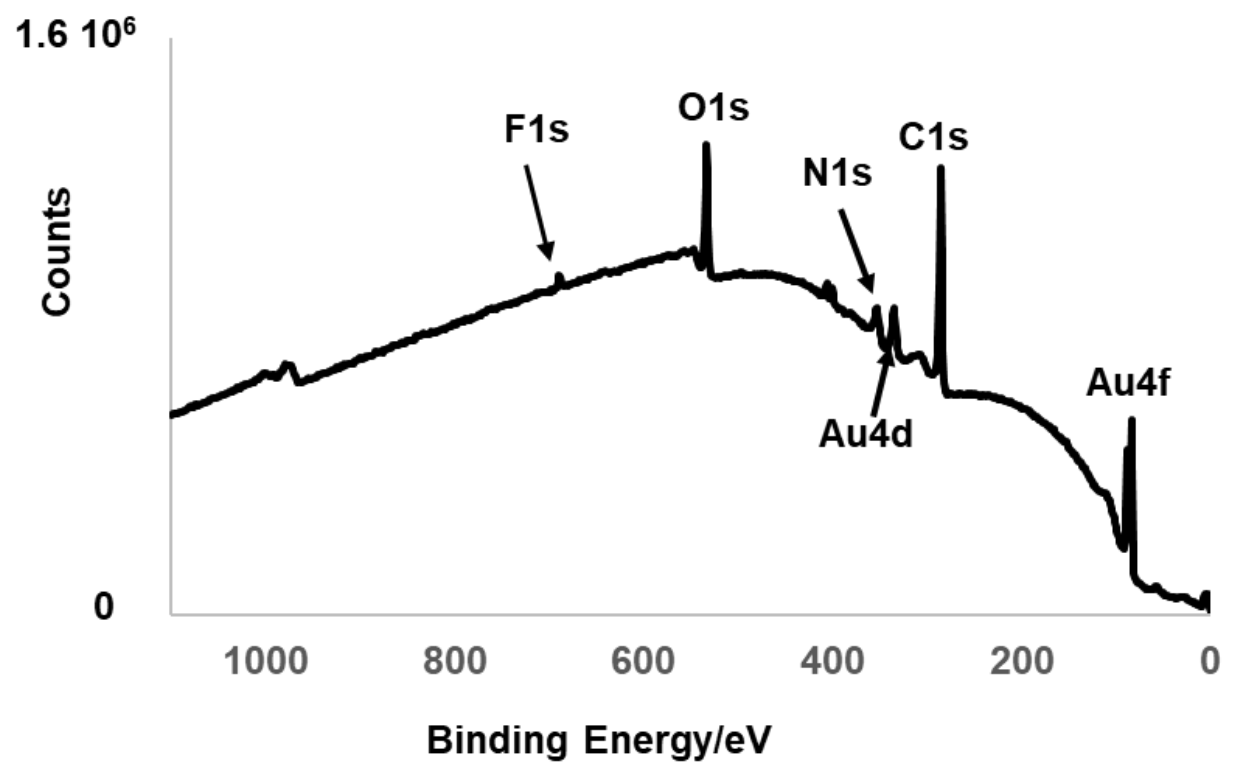

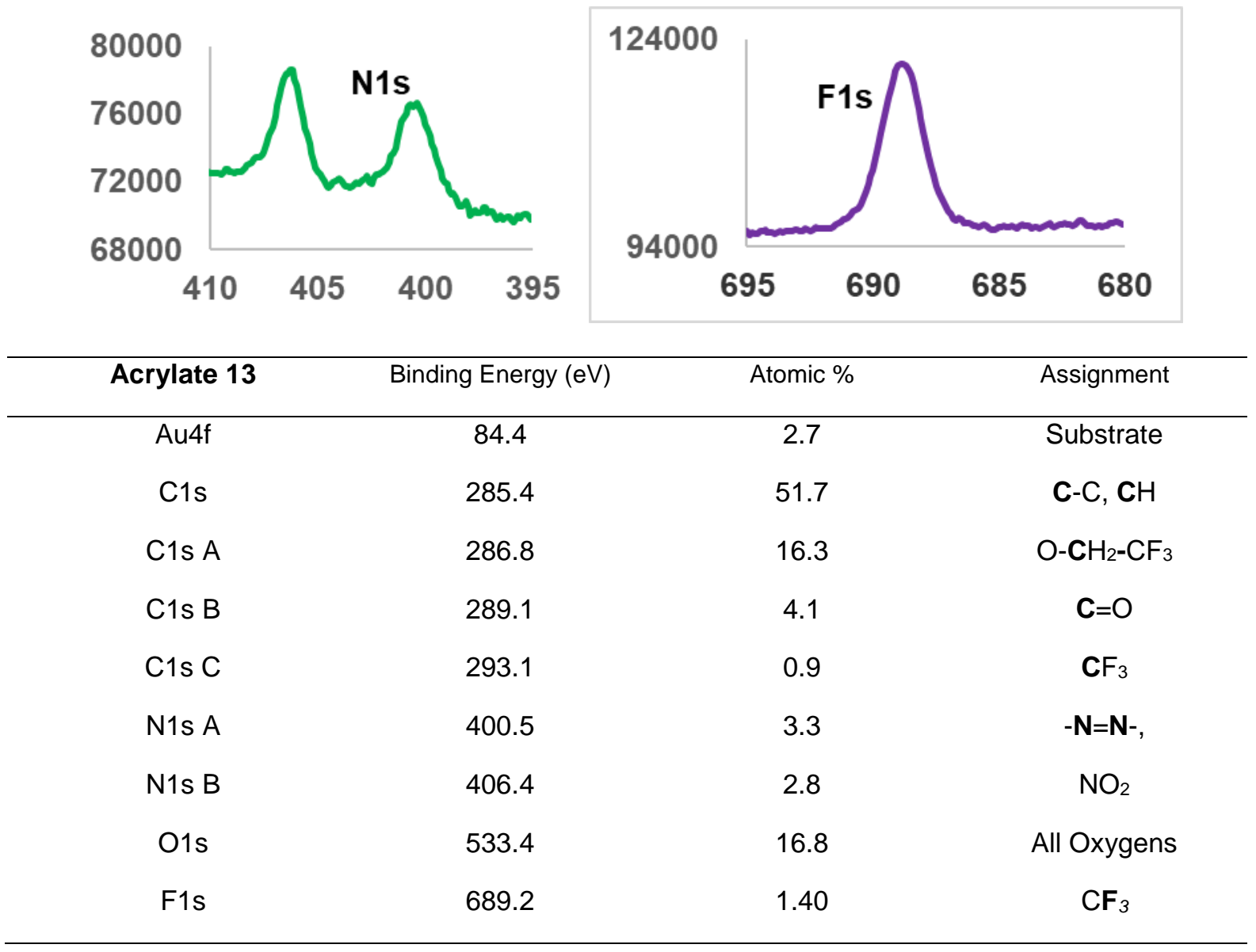


$\prod_{0}^{\circ} \mathrm{H}_{3} \mathrm{Si(OEt)_{3 }}$

14
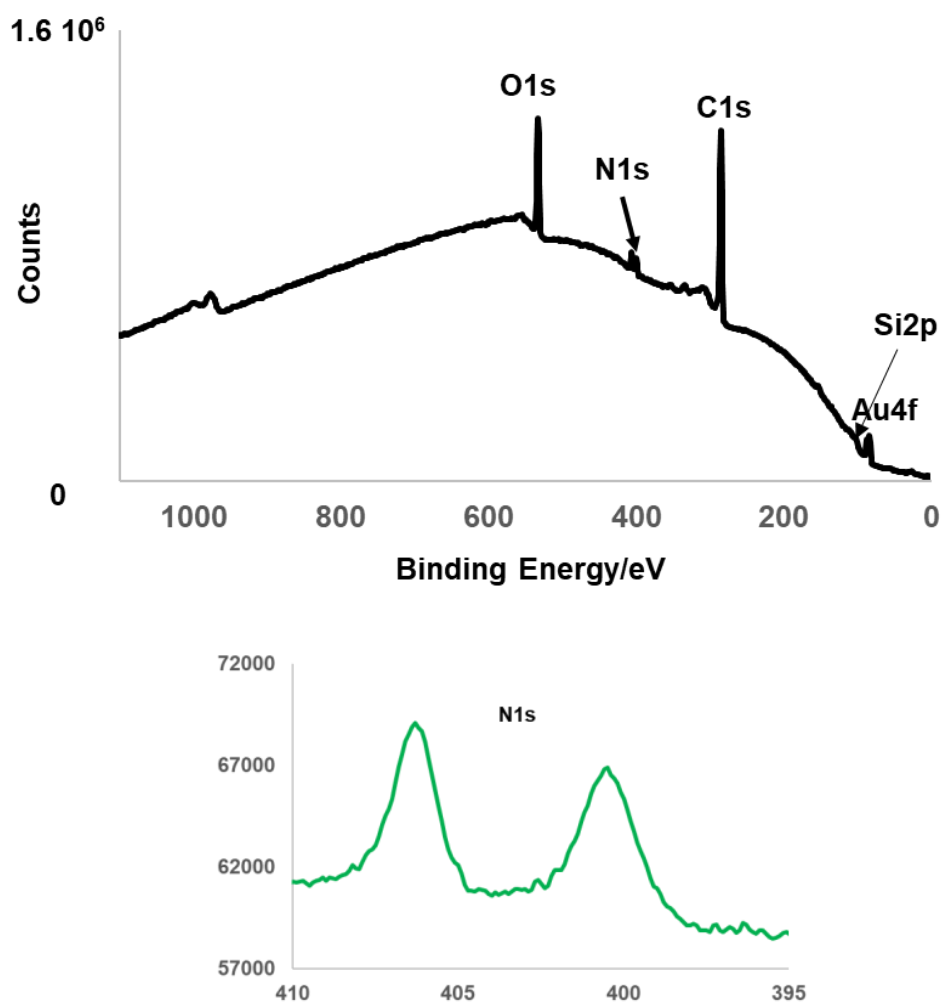

\begin{tabular}{cccc}
\hline Acrylate 14 & Binding Energy $(\mathrm{eV})$ & Atomic \% & Assignment \\
\hline Au 4f & 84.1 & 0.6 & Substrate \\
C1s & 285.3 & 53.7 & $\mathbf{C}-\mathrm{C}, \mathbf{C H}$ \\
C1s A & 286.7 & 12.9 & $-\mathrm{O}-\mathrm{CH}-\mathrm{C}$ \\
C1sB & 288.9 & 3.1 & $\mathbf{C}=\mathrm{O}$ \\
N1sA & 400.5 & 3.8 & $-\mathrm{N}=\mathrm{N}-$ \\
N1s B & 406.3 & 3.4 & $\mathrm{NO} 2$ \\
O1s & 533.1 & 20.9 & All Oxygens \\
Si2p & 102.7 & 1.6 & Substituents
\end{tabular}




\section{Examination of ferrocene film electrochemical activity.}

To visualize the ferrocene redox chemistry, ferrocene cinnamate gold modified surfaces were used as a working electrode in a Cyclic Voltammetry (CV) experiment, using a platinum mesh $\left(2.5 \mathrm{~cm}^{2}\right)$ counter and a leakless $\mathrm{Ag} / \mathrm{AgCl}$ as reference. The choice of solvent was $\mathrm{ACN}$ with Tetrabutylammonium hexafluorophosphate electrolyte $\left(\mathrm{TBAPF}_{6}, 0.1 \mathrm{M}\right)$. A potential sweep was applied between $-0.1 \mathrm{~V}$ and $+1.0 \mathrm{~V}$, at a scan rate of $100 \mathrm{mV} / \mathrm{sec}$. This suggests that there are well-isolated Fc centers within the layer, or the presence of isolated pin-holes providing solvent and ion access to Fc centers.
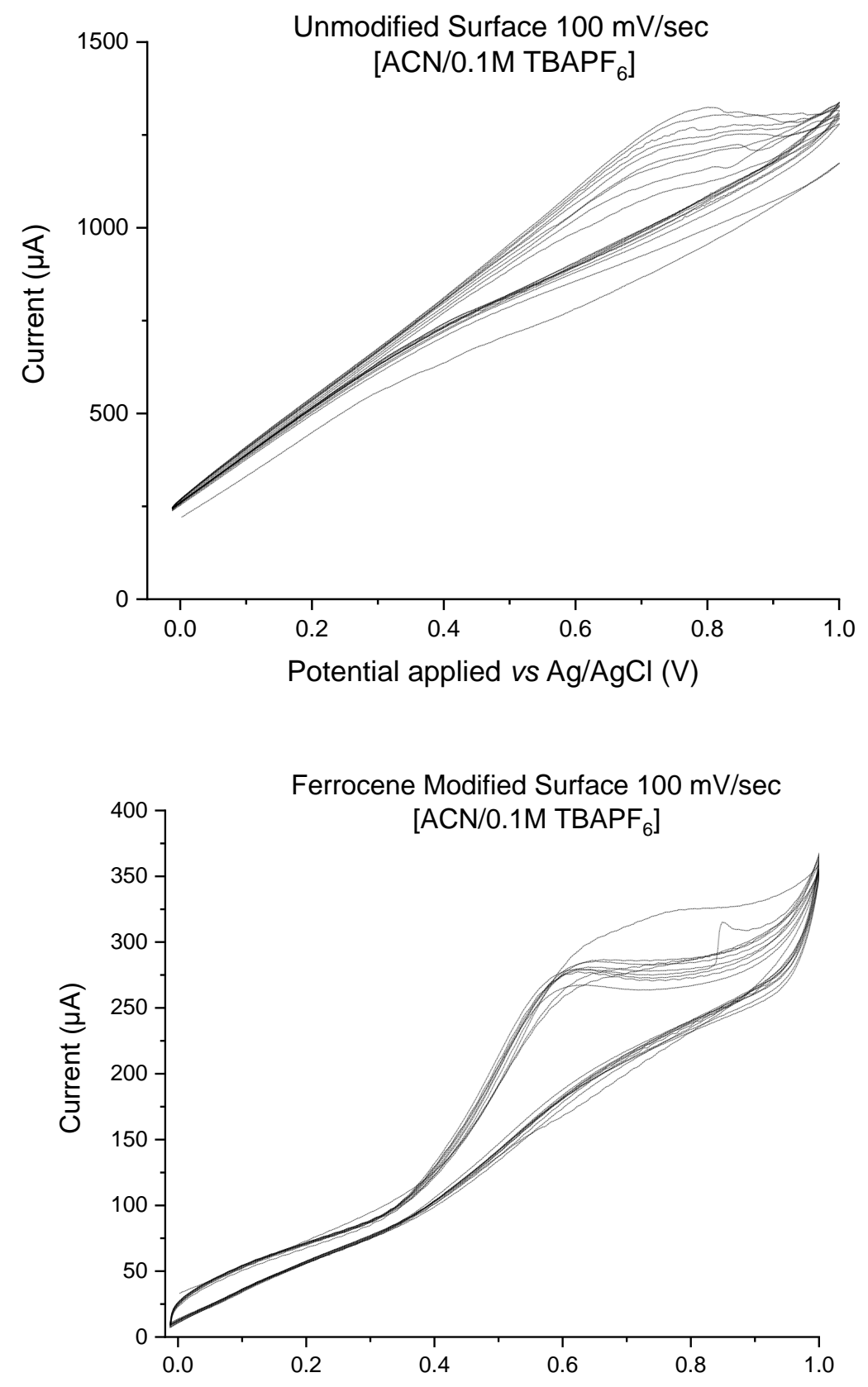

When slowing the scan rate to $10 \mathrm{mV} / \mathrm{sec}$ the electrode surface degraded and gave no electrochemical response. 


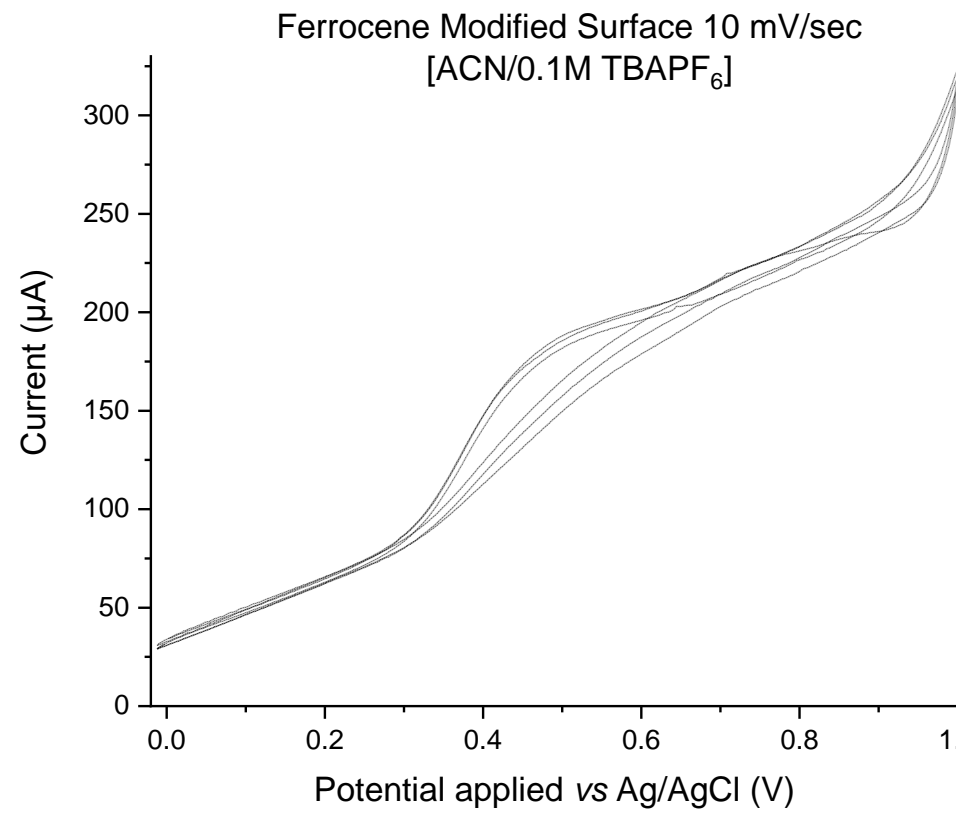

1. A. Hottin, A. Scandolera, L. Duca, D. W. Wright, G. J. Davies and J.-B. Behr, Bioorg. Med. Chem. Lett. 2016, 26, 1546-1549. 